REVISTA DE DERECHO UNED, NÚM. 26, 2020

\title{
EL REINTEGRO DE PRESTACIONES SOCIALES INDEBIDAS: EL CASO DE LAS PENSIONES NO CONTRIBUTIVAS EN ANDALUCÍA, ENTRE EL FRAUDE Y LA NECESIDAD.
}

THE REIMBURSEMENT OF UNLAWFUL SOCIAL ALLOWANCE. THE CASE OF ANDALUCIA, BETWEEN FRAUD AND NECESSITY.

\author{
JuAN RodRíGuez CADENAS \\ Doctorando en Derecho y CC Sociales UNED
}

\begin{abstract}
Resumen: Este trabajo describe el procedimiento administrativo que sigue la Tesorería General de la Seguridad Social, como Entidad Gestora, para obtener la devolución o reintegro de prestaciones percibidas indebidamente por supuestos beneficiarios, sobre todo, en el caso de las pensiones no contributivas dentro del ámbito de la Comunidad Autónoma de Andalucía. En primer lugar, se hace un pequeño bosquejo de aspectos que son comunes o generales a todas las comunidades autónomas, de acuerdo con la estructura política de España. En segundo lugar, se analizan algunos aspectos inherentes a las pensiones no contributivas: para qué son, a quienes benefician, cómo se otorgan, cuál es su cuantía y cómo se extinguen, para valorar así la incidencia en la Comunidad Autónoma de Andalucía, en cuanto a las pensiones no contributivas como parte integrante de la Seguridad Social española. Por último, se aborda el procedimiento que debe seguirse para el reintegro de las prestaciones indebidamente percibidas por parte de los beneficiarios, de acuerdo con lo dispuesto en nuestro ordenamiento jurídico, de manera que cada Comunidad Autónoma debe ser garante, tanto de la correcta asignación de las prestaciones como del retorno o reintegro de las cantidades percibidas por beneficiarios de manera indebida, sea origi-
\end{abstract}


nada por errores cometidos por la propia Administración Pública, o por omisión, falsedad o alteración intencionada de datos por parte del beneficiario.

Palabras Clave: Prestaciones No Contributivas, Seguridad Social, Comunidad Autónoma de Andalucía, Fraude y Procedimiento de Reintegro.

Abstract: This work describes the administrative procedure follwed by the Social Security General Treasury, as Management Entity, in order to obtain the refund or reimbursement of allowances unlawfully received by alleged beneficial owners, especially in the case of non-contributory benefits, within the area of Andalusia Autonomous Community. Firstly, it is made a short draft of those common or general aspects in all the autonomous communities, in accordance with the Spanish political structure. Secondly, it is analised some inherent aspects to the non-contributory benefits: what they are, who the profit, how they are bestowed, which their quantity is and how they expire. Thus, it can be valued the incidence in the Andalusia A C regarding the non-contributor benefits as an integral part the Spanish Social Security. Finally, it also deals with the proceedings which are to be followed for the reimbursementof the allowances unlawfully receivedby the beneficial owners in accordance with the procedure provided bu our legal system so that every autonomous community must be a warrantor of both, the appropriate assignment of the allowances, as wellas the drawback or reimbursement of the quantities received by the beneficial owners unlawfully, having been originated by mistake made by the Public Administration or due to default, counterfeit or intentional alteration of data by the beneficial owners.

Key Words: Allowances, Non- Contributory, Social Security, Andalusia Autonomous Community and Reimbursement Proceedings.

Recepción original: 13-1-2020

Aceptación original: 2-6-2020

Sumario: Resumen. Abstract. Introducción. Objetivos de la investigación. Generalidades de las Comunidades Autónomas. Presupuesto y distribución de rentas de las Comunidades Autónomas. Las pensiones no contributivas en la Comunidad Autónoma de Andalucía. Beneficiarios. Requisitos. Cómputo de Ingresos. Cuantía y límites. Obligaciones de los beneficiarios. Prestaciones devengadas y no percibidas. Extinción del derecho y renuncia a la pensión no contributiva Procedimiento de reintegro de prestaciones indebidamente percibidas. Derecho de la Tesorería General de la S. Social a 
obtener el reintegro de los ingresos abonados indebidamente. Competencia y plazo de resolución. Reglas de procedimiento de reintegro. Exclusión de la aplicación del procedimiento de reintegro. Reintegro de prestaciones indebidas de PNC 2013-2018. Conclusiones. 1. Dimensión económica 2. Efectos familiares. 3. Utilidad de los controles. 4. Propuestas y sugerencias. Referencias bibliográficas utilizadas. Glosario de figuras.

\section{INTRODUCCIÓN}

La Constitución Española (CE) en su artículo 41 proclama que "Los poderes públicos mantendrán un régimen público de Seguridad Social para todos los ciudadanos, que garantice la asistencia y prestaciones sociales suficientes ante situaciones de necesidad, especialmente en caso de desempleo. La asistencia y prestaciones complementarias serán libres". La Seguridad Social constituye pues un pilar esencial del Estado de Bienestar, regido por un sistema de solidaridad, destinado a la prevención y remedio de situaciones de necesidad y de riesgos personales, mediante prestaciones individualizadas y económicamente evaluables.

En este sentido, la seguridad social probablemente sea una de las mejores creaciones humanas, y, desde luego, uno de los mayores exponentes del denominado "Estado del bienestar" (García Murcia, 2017).

De la letra del propio artículo 41 de la CE se configura y garantiza "El derecho de los españoles a la Seguridad Social", que presupone la existencia de una compleja relación jurídica entre el sujeto incluido en el ámbito de aplicación de un régimen de seguridad social y la entidad que cubre los riesgos (Alonso y Tortuero, 2000), las prestaciones que son debidas a los sujetos protegidos, la obligación de reintegrar las prestaciones indebidas percibidas por estos; entre otros aspectos de importancia e interés.

Por su parte, el artículo 42 de la Ley General de Seguridad Social $(\text { LGSS })^{1}$ pone de manifiesto que la acción protectora de la Seguridad Social, comprende además de la asistencia sanitaria, determinadas prestaciones económicas (invalidez, jubilación, desempleo, incapacidad temporal, muerte y supervivencia, así como también prestaciones familiares) que otorga en dos modalidades: la contributiva y la

1 Texto Refundido aprobado por Real Decreto Legislativo 8/2015, de 30 de octubre

(C) UNED. Revista de Derecho UNED, núm. 26, 2020 
no contributiva o asistencial; siendo la segunda modalidad, esto es, las prestaciones no contributivas, el objeto de estudio del presente trabajo, puesto en relación, básicamente, con el procedimiento de reintegro de prestaciones indebidas en la Comunidad Autónoma de Andalucía.

Al respecto, vale diferenciar las prestaciones contributivas de las no contributivas, puesto que las primeras vinculan su reconocimiento a la existencia de periodos previos de actividad profesional cotizada; mientras que las segundas supeditan su existencia a un estado de necesidad conectado con la ausencia de rentas suficientes en la unidad familiar del solicitante. De esta manera, nos encontramos con que ambos tipos de prestaciones tienen fuentes de financiación diferenciadas: las contributivas lo son con cargo a las cotizaciones de empresarios y trabajadores, mientras que las no contributivas son a cargo de los Presupuestos Generales del Estado.

Es importante señalar el hecho de que en la actualidad, la gestión y financiación de la asistencia sanitaria ha sido transferida a las Comunidades Autónomas, manteniendo el Estado sólo competencias generales relativas a la coordinación de los distintos sistemas autonómicos de salud, produciéndose algunas situaciones de falta de asistencia médica, salvo urgencias, cuando se presta la atención en distinta Comunidad Autónoma a la de residencia habitual.

$\mathrm{Y}$ en lo que atañe a este estudio se debe resaltar que en el supuesto de que se perciban indebidamente prestaciones, nace la obligación de restituirlas a la Administración. En este sentido el artículo 55 de la Ley General de la S. Social establece que los trabajadores y demás personas que hayan percibido indebidamente prestaciones de la Seguridad Social, vendrán obligados a reintegrar su importe $\mathrm{y}$, asimismo, quienes hayan contribuido a hacer posible la percepción indebida de una prestación, responderán subsidiariamente con los perceptores, salvo buena fe probada. El reintegro prescribe a los cuatro años contados a partir de la fecha de cobro o desde que fuera posible ejercitar la acción para exigir su devolución y deberá realizarse de conformidad con el procedimiento establecido en la propia Ley, como bien indica el artículo 45.2 del texto legal citado, en cuanto a la exigencia de responsabilidades.

Se pretende en este trabajo abordar los aspectos antes referenciados, dividiendo el estudio en tres capítulos, donde en el primero se tratan las generalidades de las Comunidades Autónomas a los fines de verificar la estructura política en España; el segundo capítulo se refiere a las pensiones no contributivas en la Comunidad Autónoma 
de Andalucía; y, por último, el capítulo tercero describe el procedimiento para el reintegro de prestaciones indebidamente percibidas.

\section{OBJETIVOS DE LA INVESTIGACIÓN.}

Como objetivo general del presente estudio, se menciona la descripción del procedimiento de reintegro de prestaciones indebidas, con énfasis en las PNC de la Comunidad Autónoma andaluza, desprendiéndose del objetivo general tres (3) objetivos específicos, a saber :

1. Conocer los aspectos generales de las Comunidades Autónomas de España.

2. Conceptualizar las PNC en la Comunidad Autónoma de Andalucía.

3. Señalar el procedimiento aplicable para el reintegro de prestaciones indebidas.

Tales objetivos, se han diseñado con el fin de dar respuesta al título del presente estudio, donde se pretende dar a conocer cuál es el papel que desempeñan en materia de seguridad social las Comunidades Autónomas en España, qué clase de pensiones no contributivas se encuentran vigentes en la CAA y cuál es el procedimiento para reintegrar prestaciones indebidas. Todo ello enmarcado en el ordenamiento jurídico español y en las disposiciones legislativas conexas de las propias CCAA.

\section{GENERALIDADES DE LAS COMUNIDADES AUTÓNOMAS.}

Políticamente España se estructura en Comunidades Autónomas de acuerdo con lo que establece la Constitución Española (CE) de 1978, hoy vigente, en cuyo artículo 2 dice que “.....reconoce y garantiza el derecho a la autonomía de las nacionalidades y regiones que la integran...", precepto que a su vez afirma la Unidad de la Nación española y el derecho a la autonomía. Es por ello, que el propio texto de la CE establece genéricamente las "competencias" que pueden ser asumidas por las comunidades autónomas, mediante la aprobación de sus Estatutos de Autonomía, dotándolas además de sus propios órganos de gobierno e instituciones representativas. La división política y administrativa de España adopta la forma de dieciséis (16) Comunidades Autónomas y una Comunidad Foral, la de 
Navarra, que ha sido equiparada en base a jurisprudencia del Tribunal Constitucional, con idéntico estatus que el resto de las comunidades autónomas.

Se puede decir en cuanto a Andalucía, que es una comunidad autónoma constituida en 30/12/1981, donde el proceso de autonomía política se llevó a cabo a través del procedimiento restrictivo expresado en el propio artículo 151 de la CE, lo que hace de Andalucía la única comunidad española que accedió a la autonomía a través de dicho procedimiento. La Comunidad Autónoma de Andalucía tiene reconocimiento como nacionalidad histórica en el vigente Estatuto de Autonomía ${ }^{2}$ y está integrada por las provincias de Almería, Cádiz, Córdoba, Granada, Huelva, Jaén, Málaga y Sevilla, siendo ésta última la sede del Parlamento y del Consejo de Gobierno de la Junta de Andalucía.

Andalucía en cuanto Comunidad Autónoma tiene su propio Tribunal de Cuentas, Defensor del Pueblo, Consejo Consultivo y otros organismos para su buen funcionamiento, siendo Granada la sede del Consejo Consultivo y del Tribunal Superior de Justicia de Andalucía.

La CE enumera los poderes y competencias de las Comunidades Autónomas, reservándose el Estado ciertas áreas sobre las que tiene competencias exclusivas, como se describen en el artículo 149 de la $\mathrm{CE}$ y algunas otras que son compartidas ${ }^{3}$. A las Comunidades Autónomas les han sido cedidas competencias en materia de educación, sistema de salud, cultura y lengua, patrimonio, asistencia social, ordenación del territorio y urbanismo, protección del medio ambiente, transporte público, agricultura, entre otras. Las competencias transferidas van a depender en gran medida de los respectivos Estatutos de Autonomía y pueden variar considerablemente de una comunidad autónoma a otra.

2 Estatuto de Autonomía de Andalucía. Artículo 1: “Andalucía, como nacionalidad histórica y en el ejercicio del derecho de autogobierno que reconoce la Constitución, se constituye en Comunidad Autónoma en el marco de la unidad de la nación española y conforme al artículo 2 de la Constitución.”. Boletín Oficial del Estado n. 68 de 20 de marzo de 2007, página 11872.

3 Título VIII. De la Organización Territorial del Estado - Constitución Española.www.congreso.es. Consultado el 27 de febrero de 2019. 


\subsection{Presupuesto y Distribución de Rentas de las Comunidades Autónomas.}

Los artículos 156 al 158 de la CE, determinan los aspectos básicos de la financiación de las CCAA, con la finalidad de crear un sistema que garantice la obtención de los recursos necesarios para ejercer las competencias que estas administraciones territoriales han ido asumiendo. En tal sentido, se establecen los siguientes principios:

- Autonomía financiera (aunque no de forma absoluta), donde se otorga cierta libertad a las Comunidades para decidir sobre sus gastos e ingresos.

- Solidaridad, para que exista un equilibrio económico adecuado y justo entre las diversas partes del territorio.

- Igualdad, a los efectos de impedir que las diferencias entre Estatutos impliquen privilegios económicos o sociales.

- Coordinación con la Hacienda Estatal, como garantía de eficacia del funcionamiento del conjunto del Estado Autonómico.

Pese a estos principios comunes no existe un modelo único para lograr la autonomía financiera, pues la mayoría de las Comunidades se rigen por el régimen común, previsto en la Ley Orgánica 8/1980, de 22 de septiembre, de Financiación de las Comunidades Autónomas (LOFCA) el País Vasco existe un sistema de Convenio y Concierto reconocido históricamente por la Constitución.

\section{LAS PENSIONES NO CONTRIBUTIVAS EN LA COMUNIDAD AUTÓNOMA DE ANDALUCÍA.}

Las prestaciones pueden definirse como aquellas atribuciones patrimoniales, en dinero o en especie, destinadas a cubrir estados de necesidad (Almansa, 1984) y también se definen como cada uno de los derechos o beneficios que a los asegurados o favorecidos indirectos se les concede en diferentes seguros sociales (Cabanellas, 2001), y en tal sentido, las prestaciones pueden consistir en : a) indemnizaciones en dinero; b) resarcimiento en especie; c) en un servicio,

4 BOE núm. 236 de 01 octubre de 1980 
y respecto de las pensiones no contributivas este autor señala lo siguiente :

"la pensión no contributiva es aquella suma de dinero mensual, prevista en disposiciones legislativas, de mayor o menor generalidad, asignan a personas que requieren tales prestaciones por razones de edad y otra causa que emplace a la obtención de recursos por ellas mismas para su subsistencia, y con exclusión de todo aporte previo para formar los fondos con que se atenderán estos desembolsos".-

Es destacable en este caso, y eso es lo que distingue a este tipo de pensión, la circunstancia de no haber aportado fondos para ese destino, esto es, no haber realizado cotización o haberlo hecho en forma insuficiente para lucrar una pensión. No obstante, la pensión no contributiva asegura una prestación de carácter económico de cuantía determinada, asistencia médico-farmacéutica y servicios sociales complementarios.

Para la Consejería de Igualdad y Políticas Sociales de la Comunidad Autónoma de Andalucía, las pensiones no contributivas (PNC) han reparado determinados espacios de justicia social, atendiendo a personas en estado de necesidad que por no haber cotizado nunca al Sistema de Seguridad Social o haberlo hecho por tiempo insuficiente para causar derecho a la pensión contributiva, carecen, además, de rentas o ingresos mínimos para su subsistencia.

Por tanto, la gestión y reconocimiento del derecho a percibir una PNC, se realiza por las Comunidades Autónomas, debido a que tienen transferidas las funciones y servicios del Instituto de Mayores y Servicios Sociales (IMSERSO). En el caso de Andalucía, la gestión corre a cargo de la Consejería de Igualdad, Políticas Sociales y Conciliación.

La normativa básica de estas prestaciones se encuentra en el Real Decreto 357/1991, de 15 de marzo, que desarrolla en materia de pensiones no contributivas la Ley 26/1990, de 20 de diciembre, por la que se establecen dentro del Sistema de la Seguridad Social, las prestaciones no contributivas, junto al Real Decreto 771/1997, de 30 de mayo, por el que se establecen reglas de determinación de los importes de las pagas extraordinarias de las pensiones de la Seguridad Social y el Real Decreto 1191/2012, de 3 de agosto, por el que se establecen normas para el reconocimiento del complemento de pensión para el alquiler de vivienda a favor de pensionistas de una PNC. 
Se debe indicar que existen dos tipos de PNC: 1.-) de jubilación, 2.-) de invalidez, que se concretan en ambos casos en una prestación económica; el derecho a la asistencia médico-farmacéutica gratuita y a los servicios sociales complementarios. La cobertura económica o prestación se determina anualmente por la Ley de Presupuestos Generales del Estado.

\subsection{Beneficiarios.}

Tienen derecho al percibo de las PNC tanto las personas de nacionalidad y residencia españolas, como las nacionales de otros países que tengan residencia legal en España, siendo por tanto beneficiarias de estas prestaciones. Es destacable el hecho de que muchos de estos beneficiarios son mujeres que han trabajado toda su vida sin ningún reconocimiento social o económico, como ocurre en la mayoría de zonas rurales. En consecuencia, las personas que obtienen el derecho a estas PNC se convierten en pensionistas de la Seguridad Social con las mismas garantías y los mismos beneficios que el resto de pensionistas el sistema, recibiendo:

— Una prestación económica mensual.

- Asistencia sanitaria y médico-farmacéutica gratuita

- Servicios Sociales y Ayudas complementarias

\subsection{Requisitos.}

Para el caso de las PNC que se otorgan en la CAA, los requisitos son de dos categorías a) de carácter general y b) de carácter específico. Siendo el requisito general que la persona carezca de ingresos suficientes, pudiendo originarse esta condición por las siguientes situaciones:

- Para el año 2018 en la CAA, la cuantía máxima anual de la PNC fue de 5.321,40 euros; en tal sentido, si la persona vivía sola y sus rentas o ingresos computables de las que se disponía eran inferiores a la cuantía máxima anual indicada, el criterio a aplicar era que esa persona podía obtener una PNC por carecer de ingresos.

- Por el contrario, si la persona convivía con familiares, en este supuesto se atiende al grado de parentesco de los familiares 
con los que conviva, el número de ellos y el volumen de rentas o ingresos totales de la unidad económica de convivencia (UEC), a los fines de determinar si puede o no ser beneficiaria de la PNC.

Adicionalmente, se consideran también los requisitos de carácter específico, los cuales se asocian a situaciones de: jubilación e invalidez. Para la obtención de una PNC de jubilación deben cumplirse con los siguientes requisitos:

- Es necesario que el/la solicitante en el momento de la solicitud, haya cumplido los 65 años de edad.

- El/la solicitante debe residir en territorio español o en el territorio de algún país miembro de la Unión Europea durante 10 años; para este caso, debe considerarse el periodo que media entre la fecha en que la persona solicitante hubiese cumplido los 16 años y la de devengo de la pensión, dos de los cuales han de ser consecutivos e inmediatamente anteriores a la fecha de solicitud.

Por último, para el caso de las PNC por causa de invalidez, sus requisitos son los siguientes:

- Para la fecha de la solicitud, la persona debe ser mayor de 18 años y menor de 65 años de edad.

- Residir en el territorio español o en el territorio de algún país miembro de la UE durante un periodo de 5 años, de los que 2 han de ser consecutivos e inmediatamente anteriores a la fecha de presentación de la solicitud.

- La persona solicitante debe estar afectada por una discapacidad o por una enfermedad crónica, en un grado igual o superior al $65 \%$.

- En los casos de presentar un grado de discapacidad igual o mayor al 75\% y se acredite la necesidad del concurso de otra persona, mediante la superación del baremo establecido, se percibirá un complemento del $50 \%$ del importe máximo anual.

El vigente artículo 367.3 del Real Decreto Legislativo 8/2015, de 30 de octubre, por el que se aprueba el Texto Refundido de la Ley General de la Seguridad Social, establece que "Las pensiones de in- 
validez no contributivas, cuando sus beneficiarios cumplan la edad de sesenta y cinco años, pasarán a denominarse pensiones de jubilación. La nueva denominación no implicará modificación alguna respecto a las condiciones de la prestación que viniesen percibiendo". Por tal razón, el beneficiario de este tipo de PNC no tiene que realizar ninguna actuación y continuará percibiendo la prestación siempre y cuando mantenga los requisitos de recursos y de residencia legal, ya que la discapacidad no le será revisada a estos efectos.

\subsection{Cómputo de Ingresos.}

Los recursos computables incluyen todos los ingresos percibidos por la persona solicitante y por los familiares que convivan en la unidad económica de convivencia (UEC) en el año de la solicitud; por lo tanto, a los fines del otorgamiento de la PNC, se consideran rentas o ingresos computables los bienes y derechos de que dispongan anualmente la persona beneficiaria o la UEC, derivados tanto del trabajo como del capital, así como cualesquiera otros sustitutivos de aquellos, computándose por su importe íntegro o bruto. No obstante, se excluyen como parte de tales ingresos computables, los siguientes:

- Prestación económica por hijo a cargo, con o sin condición de persona con discapacidad.

- Las deducciones fiscales de pago directo por hijos menores a cargo.

- El subsidio de movilidad y compensación para gastos de transporte.

- Premios o recompensas otorgadas a personas con discapacidad en los centros ocupacionales.

- Subvenciones, ayudas o becas destinadas a compensar un gasto realizado.

- Las prestaciones económicas y en especie otorgadas al amparo de la Ley 39/2006, de 14 de diciembre, de promoción de la autonomía personal y atención a las personas en situación de dependencia.

- Ayudas sociales para mujeres víctimas de violencia de género reguladas por el Real Decreto 1452/2005, de 2 de diciembre, en virtud del art. 27 de la Ley Orgánica 1/2004, de 28 de di- 
ciembre, de Medidas de Protección Integral contra la Violencia de Género.

Por otra parte, a las personas beneficiarias de la PNC de invalidez que inicien actividad laboral por cuenta propia o ajena, les serán de aplicación el Real Decreto Legislativo 8/2015 de 30 de octubre, para compatibilizar dicha pensión con el trabajo remunerado. No se les tendrán en cuenta en el cómputo anual de rentas propias las que hubiera percibido en virtud de su trabajo y/o subsidios por desempleo, en el ejercicio en que se reponga el pago de la pensión.

Por consiguiente, la pensión es compatible con cualquier otra prestación, ayuda o subsidio, con la obligación de declarar en un plazo máximo de 30 días los ingresos percibidos por estos conceptos, a efectos del cálculo de los ingresos económicos de la unidad económica de convivencia, para la determinación del derecho a la pensión y, en su caso, para la determinación de la cuantía, dando lugar, en otro caso, al procedimiento de reintegro por estimarse como indebidamente percibida la prestación.

\subsection{Cuantía y límites.}

Las PNC de jubilación e invalidez se financian con cargo al Presupuesto del Estado para la Seguridad Social, figurando el crédito en el presupuesto del Instituto de Mayores y Servicios Sociales, y abonándose las pensiones a través de la Tesorería General de la Seguridad Social. El importe básico anual se fija en la Ley de Presupuestos Generales del Estado, distribuyéndose en 12 mensualidades más dos pagas extraordinarias, y señala también las cuantías máxima y mínima de la PNC, con arreglo a los siguientes criterios : a) para establecer la cuantía de la pensión para cada persona beneficiaria se fija en función de sus ingresos y rentas personales. b) en los casos de los miembros que convivan en su UEC, la PNC no puede ser inferior a la cuantía mínima, ni superior a la cuantía máxima, igualmente en cómputo anual.

La cuantía individual de cada beneficiario se determina en base a la cuantía básica indicada y en función del número de beneficiarios de PNC integrados en la misma unidad económica de convivencia y de los recursos de que dispongan el interesado y/o las personas que componen dicha unidad económica de convivencia.

En la CAA se estableció para el Ejercicio 2019 la actualización y revalorización de las PNC del 3\%, en relación al ejercicio 2018, se- 
gún establece el Real Decreto-ley 28/2018, de 28 de diciembre, para la revalorización de las pensiones públicas y otras medidas urgentes en materia social, laboral y de empleo. Para el año 2020 se aplicó la revalorización del 0.9\%, prevista en el Real Decreto-Ley 1/2020, de 14 de enero, siendo los importes vigentes de las PNC de jubilación e invalidez los que se recogen en los cuadros siguientes:

\section{Pensiones de Jubilación e Invalidez Año 2020}

\section{$n^{o}$ 1.- Cuantías por número de Convivientes}

\begin{tabular}{lcc}
\hline & $\begin{array}{c}\text { NÚMERO DE } \\
\text { CONVIVIENTES }\end{array}$ & EUROS/AÑo \\
\hline $\begin{array}{l}\text { Si convive sólo con su cónyuge y/o } \\
\text { parientes consanguíneos de segundo } \\
\text { grado (hermano-hermana, nieto-nieta o } \\
\text { abuelo-abuela) }\end{array}$ & 2 & $9.415 .28 €$ \\
\cline { 2 - 3 } & 3 & $13.292 .16 €$ \\
\cline { 2 - 3 } $\begin{array}{l}\text { Si entre los parientes consanguíneos } \\
\text { con los que convive se encuentra alguno } \\
\text { de primer grado (padres y madres o hijos }\end{array}$ & 4 & $17.169 .04 €$ \\
\cline { 2 - 3 } e hijas) & 2 & $21.045 .92 €$ \\
\cline { 2 - 3 } & 5 & $23.538 .20 €$ \\
\hline
\end{tabular}

Fuente: https://www.juntadeandalucia.es/organismos/igualdadpoliticassocialesyconciliacion/areas/pensiones/pensiones-no-contributivas.html

$$
\text { no } 2 \text {.- Cuantías Básicas }
$$

\begin{tabular}{lccc}
\hline & ANUAL & MENSUAL & N PAGAS $^{\circ}$ \\
\hline $\begin{array}{l}\text { Cuantía Máxima 1 } \\
\text { Beneficiario }\end{array}$ & $5.538 .40 €$ & $395.60 €$ & 14 \\
\hline $\begin{array}{l}\text { Cuantía Mínima: }(25 \% \text { de la } \\
\text { máxima) }\end{array}$ & $1.384 .60 €$ & $98,90 €$ & 14 \\
\hline $\begin{array}{l}\text { Invalidez: Complemento } \\
(50 \% \text { de la Máxima) }\end{array}$ & $2.769 .20 €$ & $197.80 €$ & 14 \\
\hline $\begin{array}{l}\text { Integra Invalidez: } \\
\text { Complemento (50\% de la } \\
\text { Máxima) }\end{array}$ & $8.307 .60 €$ & $593,00 €$ & 14 \\
\hline
\end{tabular}

Fuente: https:/www.juntadeandalucia.es/organismos/igualdadpoliticassocialesyconciliacion/areas/pensiones/pensiones-no-contributivas.html 
$n^{\circ}$ 3.- Importe máximo anual con más de un beneficiario en la UEC

En caso de convivir dos o más personas beneficiarias/titulares de PNC dentro de la misma UEC el importe máximo anual de la pensión para cada uno es el que se indica a continuación:

\begin{tabular}{cccc}
\hline & ANUAL & MENSUAL & N $^{\mathbf{0}}$ PAGAS \\
\hline 2 Titulares & $4.707 .64 €$ & $336.26 €$ & 14 \\
\hline 3 Titulares & $4.430 .72 €$ & $316.48 €$ & 14 \\
\hline 4 Titulares & $4.292 .26 €$ & $306.59 €$ & 14 \\
\hline 5 Titulares & $4.209 .18 €$ & $300.66 €$ & 14 \\
\hline
\end{tabular}

Fuente: https://www.juntadeandalucia.es/organismos/igualdadpoliticassocialesyconciliacion/areas/pensiones/pensiones-no-contributivas.html

\subsection{Obligaciones de los beneficiarios.}

Los perceptores de las pensiones de invalidez y jubilación en la modalidad de PNC, estarán obligados a comunicar, en el plazo máximo de 30 días desde la fecha en que se produzca, cualquier variación de su situación de convivencia, tales como: estado civil, residencia, recursos económicos propios o ajenos computables por razón de convivencia, baja de algún miembro de la UEC (por traslado de domicilio, fallecimiento, etc.), variación en los ingresos de la UEC, fallecimiento de la persona beneficiaria y cualquier otra circunstancia que pudiera tener incidencia en la PNC.

En tal sentido, cuando la persona beneficiaria de una PNC perciba una prestación de Renta Activa de Inserción (RAI), deberá comunicarlo de forma inmediata a la Delegación Territorial de la Consejería de Igualdad y Políticas Sociales de su provincia, ya que mientras dure la percepción de la RAI, se le deberá suspender del derecho de la PNC y a la asistencia sanitaria y farmacéutica gratuitas. No comunicarlo, genera de inmediato la obligación de reintegrar las cantidades indebidamente percibidas.

Por otra parte, las personas beneficiarias de las PNC están obligadas a presentar una Declaración Anual (en el primer trimestre de cada año) de los ingresos o rentas computables de toda la UEC, referidos al año inmediato anterior. Al mismo tiempo, declararán las posibles variaciones en los ingresos o rentas justificados, referidos al año en curso. En caso de incumplimiento de dicha obligación, y previo requerimiento del organismo gestor a la persona beneficiaria, con 
la advertencia expresa de las consecuencias del incumplimiento, se procederá, como medida cautelar, a suspender el pago de la pensión.

\subsection{Prestaciones Devengadas y No Percibidas.}

En el supuesto de fallecimiento del solicitante o beneficiario de PNC, sus herederos podrán solicitar las cuantías devengadas y no percibidas por el interesado. En estos casos deberá presentarse conjuntamente con la solicitud debidamente cumplimentada; certificado de defunción, número de cuenta bancaria en la que figure como titular el solicitante de la prestación devengada y no percibida, copia del DNI del solicitante de la prestación devengada o autorización para consulta de ficheros, copia del libro de familia, copia autorizada del testamento o, en el caso de no haberlo otorgado, certificado de últimas voluntades.

\subsection{Extinción del Derecho y Renuncia a la Pensión no Contributiva.}

Cuando concurra alguna de las siguientes circunstancias, se producirá la extinción del derecho a la PNC:

a. Pérdida de la condición de residente legal o traslado de la residencia fuera del territorio español por tiempo superior a noventa días.

b. Disponer de rentas o ingresos suficientes, es decir, superar los límites de acumulación de recursos fijados para cada caso.

c. En el caso de las PNC de invalidez, la mejoría de la discapacidad o enfermedad crónica padecida que determine un grado inferior al 65 por 100 .

d. Fallecimiento de la persona beneficiaria.

Se ha de indicar también, que el derecho al reconocimiento de las PNC es irrenunciable de acuerdo con lo que dispone el artículo 3 del TRLG de Seguridad Social que dice : "Será nulo todo pacto, individual o colectivo, por el cual el trabajador renuncie a los derechos que le confiere la presente ley". Sin embargo, se admite la renuncia a la PNC en el caso de cuantía mínima a efectos de acceder al complemento por cónyuge a cargo, siempre que ello sea más ventajoso, económicamente, para la unidad familiar. 
Cuando se produce cualquiera de las mencionadas circunstancias, nace de inmediato la obligación de reintegro o devolución de lo que resulte indebidamente percibido, siendo los motivos más habituales la falta de comunicación en tiempo hábil del fallecimiento del beneficiario, lo que provoca se sigan efectuando ingresos mensuales en la cuenta bancaria donde se halle domiciliada la prestación, y la variación de rentas producida dentro del seno de la UEC, cuando alguno o más de un miembro de dicha unidad perciba rentas o ingresos que superen los límites inicialmente establecidos.

\section{PROCEDIMIENTO DE REINTEGRO DE PRESTACIONES INDEBIDAMENTE PERCIBIDAS.}

La obligación de reintegro, para trabajadores y demás personas, que hayan percibido indebidamente prestaciones de la Seguridad Social, se encuentra establecida en el artículo 55 del TR de la Ley General de la Seguridad Social (RDLeg. 8/2015), y el procedimiento especial para el reintegro de las prestaciones de la Seguridad Social indebidamente percibidas, está regulado en el Real Decreto $359 / 2009$, de 20 de marzo, y en aquellos casos en que no pueda ser aplicado, lo será de manera supletoria por el contenido del artículo 80 del Real Decreto 1415/2004, de 11 de junio, que aprueba el Reglamento General de Recaudación de la S. Social.

\subsection{Derecho de la Tesorería General de la S. Social a obtener el reintegro de los ingresos abonados indebidamente.}

Si como consecuencia del incumplimiento de alguna de las obligaciones por parte del beneficiario de una PNC, se derivara una percepción indebida de prestaciones, la persona beneficiaria deberá reintegrar las cantidades indebidamente percibidas desde el primer día del mes siguiente a aquel en que hubiera variado la situación, cualquiera que sea el momento en que se detecte la misma, salvo que la acción para solicitar la devolución hubiera prescrito.

De modo que la persona beneficiaria de una PNC no debe esperar a la revisión anual para comunicar aquellas variaciones que puedan afectar a la cuantía de la pensión, evitando de esta forma las posibles reclamaciones de cantidades percibidas indebidamente.

De acuerdo con al Artículo 31.3 del Real Decreto Legislativo $8 / 2015$, del 30 de octubre, las devoluciones de ingresos indebidos in- 
cluirán el interés de demora desde la fecha de su ingreso en la Tesorería General de la Seguridad Social hasta la fecha de la propuesta de pago, sin que proceda la devolución de cuotas u otros recursos que hayan sido ingresados maliciosamente, sin perjuicio de la responsabilidad de todo orden a que hubiera lugar.

Los ingresos que, en virtud de resolución judicial firme, resulten o se declaren objeto de devolución por los interesados tendrán la consideración de ingresos indebidos y serán objeto de devolución en los términos fijados en dicha resolución (art. 106, Ley 29/1998, de 13 de julio), cuando la Administración de la Seguridad Social fuera condenada al pago de una cantidad líquida, o de lo dispuesto en la Ley General Presupuestaria, en otro caso.

El derecho a la devolución de ingresos indebidos de cuotas prescribirá a los cuatro años, a contar desde el día siguiente a su ingreso. Una vez reconocida la procedencia de la devolución, el derecho a exigir su pago caducará a los cuatro años a contar desde la fecha de notificación del acto de reconocimiento. En este sentido, las sentencias del TSJ Castilla-La Mancha, de 20/01/2000 y TSJ Madrid, de 20/07/1999, han sentado el criterio de que el derecho a la devolución de ingresos indebidos de cuotas prescribirá a los cuatro años, a contar desde el día siguiente a su ingreso. Una vez reconocida la procedencia de la devolución, el derecho a exigir su pago caducará a los cuatro años a contar desde la fecha de notificación del acto de reconocimiento.

En tal sentido, las Sentencias del Tribunal Supremo-Sala $4^{\mathrm{a}}$ de lo Social- de fecha 16/02/2016 dictadas en los Recursos 1931/2014 y 2938/2014, en relación con la obligación de reintegro del importe de las prestaciones indebidamente percibidas, considera que el plazo de prescripción de cuatro años comienza a correr desde la fecha de emisión del Acta de la Inspección de Trabajo.

El derecho a la devolución de ingresos distintos de cuotas o demás conceptos de recaudación conjunta y asimilados a aquéllas se sujetará a los plazos de prescripción establecidos en las normas aplicables a la naturaleza de tales recursos.

Serán a cargo de la Entidad Gestora o Colaboradora por cuya cuenta se efectúe la devolución de ingresos indebidos los intereses de demora que se satisfagan a los interesados, el importe del reembolso de los costes de las garantías aportadas para suspender el procedimiento de recaudación y los intereses que procedan sobre éste. 
Como indica el artículo 55 de la LGSS, ya citado, la obligación de reintegro de los trabajadores y demás personas que hubieran percibido indebidamente prestaciones de la Seguridad Social, tienen obligación de reintegrar quienes por acción u omisión contribuyeran a hacer posible la percepción indebida de una prestación, deben responder subsidiariamente con los perceptores, salvo que se acredite buena fe probada, sin perjuicio de la exigencia de la responsabilidad administrativa o penal que legalmente correspondiera a aquéllos. La obligación de reintegro del importe de las prestaciones indebidamente percibidas prescribiría a los cuatro años, contados a partir de la fecha de su cobro, o desde que fue posible ejercitar la acción para exigir su devolución, con independencia de la causa que originó la percepción indebida, incluidos los supuestos de revisión de las prestaciones por error imputable a la entidad gestora.

\subsection{Competencia y plazo de resolución.}

En primer lugar, le corresponde a la Tesorería General de la Seguridad Social, conforme a la distribución de competencias que ésta tenga establecida, resolver sobre la procedencia de la devolución de las cantidades ingresadas indebidamente. Será entonces la Tesorería General de la Seguridad Social quien resolverá las solicitudes presentadas o las remitirá, cuando proceda, al organismo correspondiente junto a la documentación presentada para la adopción de la resolución procedente.

En segundo término, corresponderá la resolución a los órganos u organismos gestores, en el supuesto de que la devolución se refiera a los conceptos de recaudación conjunta con las cuotas. En este caso, estos órganos comunicarán a la Tesorería General de la Seguridad Social sus resoluciones, una vez sean firmes en vía administrativa.

En aquellos otros casos donde la devolución se solicite como consecuencia de errores materiales o de cálculo, por duplicidades de ingreso o por exceso sobre el tope máximo absoluto de la base de cotización, por períodos posteriores a la fecha de efectos de la baja o después de haber prescrito la acción para exigir su pago, o en cualquier supuesto en que la resolución de devolución deba basarse exclusivamente en la comprobación material, aritmética o contable o en el simple cómputo de los extremos alegados por los interesados, no se requerirá resolución previa de los aludidos órganos u organismos gestores. 
En cualquier caso, la resolución deberá adoptarse y notificarse dentro de los seis meses siguientes a la fecha en que se hubiera completado la documentación que deba aportar el solicitante de la devolución. Transcurrido dicho plazo sin que haya recaído resolución expresa, podrá entenderse desestimada la solicitud.

\subsection{Reglas de procedimiento de reintegro.}

El Real Decreto 148/1996, de 5 de febrero, regula el procedimiento especial para el reintegro de las prestaciones de la Seguridad Social indebidamente percibidas. El procedimiento se inicia, por acuerdo de la entidad gestora o colaboradora, administración u organismo público correspondiente, tan pronto tenga conocimiento de los hechos o circunstancias que evidencien la existencia de deudas de tal naturaleza, tramitándose en un solo expediente que debe resolverse en el plazo máximo de tres meses, contados a partir de la fecha del mencionado acuerdo que debe ser notificado al interesado.

Como indica la normativa vigente, la entidad gestora, debe dar audiencia al interesado antes de redactar la propuesta de resolución, con la finalidad de informarle acerca de las actuaciones practicadas y los hechos o datos conocidos y consecuencias que de ellos se deriven, para que de esta manera el sujeto responsable pueda presentar las alegaciones o documentos que estime conveniente.

A estos efectos, la entidad gestora o colaboradora, administración u organismo remitirá a la Tesorería General de la Seguridad Social las citadas resoluciones o acuerdos firmes en vía administrativa, con indicación del momento en que se hubiese realizado su notificación al sujeto responsable y de si han sido o no impugnadas ante los tribunales.

De igual manera, en caso de ser procedente de conformidad al artículo 4 del RD 148/1996, de 5 de febrero, se efectuará propuesta de reintegro de la deuda, sobre determinación de descuentos, a fin de que el interesado manifieste su conformidad o formule propuestas alternativas; siempre que de las mismas resulten unas cuantías superiores a las que se derivan de las mencionadas reglas. Para ello, se concederá al interesado un plazo de 15 días, contados a partir del día siguiente a aquel en que tenga lugar la notificación.

Recibidas las alegaciones o documentos del interesado o transcurrido el plazo concedido sin que éste se manifieste, se dictará la resolución que corresponda a la vista de todos los datos obrantes en 
el expediente, que será motivada y hará mención expresa de los siguientes extremos:

- Determinación de las causas que han motivado la deuda, con la indicación del período al que ésta se refiere y su cuantía.

- Fijación, en su caso, de la nueva cuantía de la prestación que corresponda percibir y fecha de efectos económicos.

- Procedencia del reintegro de las cantidades indebidamente percibidas, especificando el procedimiento para hacerlo efectivo y, en su caso, determinación del importe y plazo del descuento.

- Plazo y órgano ante el que puede interponerse reclamación previa.

La entidad gestora al notificar la resolución, debe también informar al deudor sobre la posibilidad de abonar de manera voluntaria el importe íntegro de la deuda en un solo plazo, dentro de los treinta días siguientes al de dicha notificación, suministrando incluso los formularios propios para efectuar dicho ingreso.

Transcurrido el plazo señalado sin que el deudor acredite haber efectuado el pago de la deuda, mediante el correspondiente recibo justificativo del mismo, se aplicarán los descuentos fijados en la resolución de la entidad gestora.

Para el reintegro de las citadas prestaciones, la Tesorería General de la Seguridad Social expedirá reclamación de deuda en la que se fijará el plazo reglamentario para el reintegro, que comenzará con la notificación de dicha reclamación y finalizará el último día hábil del mes siguiente al de aquella notificación, pudiendo el sujeto obligado solicitar el establecimiento de diversos plazos reglamentarios para tal devolución.

Los órganos de la Tesorería General de la Seguridad Social, podrán establecer dichos plazos reglamentarios, hasta un máximo de cinco años, cuando la situación económica y demás circunstancias concurrentes, discrecionalmente apreciadas por el órgano competente para resolver, impidan efectuar el reintegro en el plazo indicado en la reclamación. En caso de denegación de la solicitud, la resolución dará un nuevo plazo de ingreso de 15 días desde la notificación de la resolución, salvo que fuere mayor la parte del plazo que reste para el pago fijado en la reclamación de deuda. 
REVISTA DE DERECHO UNED, NÚM. 26, 2020

\title{
EL REINTEGRO DE PRESTACIONES SOCIALES INDEBIDAS: EL CASO DE LAS PENSIONES NO CONTRIBUTIVAS EN ANDALUCÍA, ENTRE EL FRAUDE Y LA NECESIDAD.
}

THE REIMBURSEMENT OF UNLAWFUL SOCIAL ALLOWANCE. THE CASE OF ANDALUCIA, BETWEEN FRAUD AND NECESSITY.

\author{
JuAN RodRíGuez CADENAS \\ Doctorando en Derecho y CC Sociales UNED
}

\begin{abstract}
Resumen: Este trabajo describe el procedimiento administrativo que sigue la Tesorería General de la Seguridad Social, como Entidad Gestora, para obtener la devolución o reintegro de prestaciones percibidas indebidamente por supuestos beneficiarios, sobre todo, en el caso de las pensiones no contributivas dentro del ámbito de la Comunidad Autónoma de Andalucía. En primer lugar, se hace un pequeño bosquejo de aspectos que son comunes o generales a todas las comunidades autónomas, de acuerdo con la estructura política de España. En segundo lugar, se analizan algunos aspectos inherentes a las pensiones no contributivas: para qué son, a quienes benefician, cómo se otorgan, cuál es su cuantía y cómo se extinguen, para valorar así la incidencia en la Comunidad Autónoma de Andalucía, en cuanto a las pensiones no contributivas como parte integrante de la Seguridad Social española. Por último, se aborda el procedimiento que debe seguirse para el reintegro de las prestaciones indebidamente percibidas por parte de los beneficiarios, de acuerdo con lo dispuesto en nuestro ordenamiento jurídico, de manera que cada Comunidad Autónoma debe ser garante, tanto de la correcta asignación de las prestaciones como del retorno o reintegro de las cantidades percibidas por beneficiarios de manera indebida, sea origi-
\end{abstract}


nada por errores cometidos por la propia Administración Pública, o por omisión, falsedad o alteración intencionada de datos por parte del beneficiario.

Palabras Clave: Prestaciones No Contributivas, Seguridad Social, Comunidad Autónoma de Andalucía, Fraude y Procedimiento de Reintegro.

Abstract: This work describes the administrative procedure follwed by the Social Security General Treasury, as Management Entity, in order to obtain the refund or reimbursement of allowances unlawfully received by alleged beneficial owners, especially in the case of non-contributory benefits, within the area of Andalusia Autonomous Community. Firstly, it is made a short draft of those common or general aspects in all the autonomous communities, in accordance with the Spanish political structure. Secondly, it is analised some inherent aspects to the non-contributory benefits: what they are, who the profit, how they are bestowed, which their quantity is and how they expire. Thus, it can be valued the incidence in the Andalusia A C regarding the non-contributor benefits as an integral part the Spanish Social Security. Finally, it also deals with the proceedings which are to be followed for the reimbursementof the allowances unlawfully receivedby the beneficial owners in accordance with the procedure provided bu our legal system so that every autonomous community must be a warrantor of both, the appropriate assignment of the allowances, as wellas the drawback or reimbursement of the quantities received by the beneficial owners unlawfully, having been originated by mistake made by the Public Administration or due to default, counterfeit or intentional alteration of data by the beneficial owners.

Key Words: Allowances, Non- Contributory, Social Security, Andalusia Autonomous Community and Reimbursement Proceedings.

Recepción original: 13-1-2020

Aceptación original: 2-6-2020

Sumario: Resumen. Abstract. Introducción. Objetivos de la investigación. Generalidades de las Comunidades Autónomas. Presupuesto y distribución de rentas de las Comunidades Autónomas. Las pensiones no contributivas en la Comunidad Autónoma de Andalucía. Beneficiarios. Requisitos. Cómputo de Ingresos. Cuantía y límites. Obligaciones de los beneficiarios. Prestaciones devengadas y no percibidas. Extinción del derecho y renuncia a la pensión no contributiva Procedimiento de reintegro de prestaciones indebidamente percibidas. Derecho de la Tesorería General de la S. Social a 
obtener el reintegro de los ingresos abonados indebidamente. Competencia y plazo de resolución. Reglas de procedimiento de reintegro. Exclusión de la aplicación del procedimiento de reintegro. Reintegro de prestaciones indebidas de PNC 2013-2018. Conclusiones. 1. Dimensión económica 2. Efectos familiares. 3. Utilidad de los controles. 4. Propuestas y sugerencias. Referencias bibliográficas utilizadas. Glosario de figuras.

\section{INTRODUCCIÓN}

La Constitución Española (CE) en su artículo 41 proclama que "Los poderes públicos mantendrán un régimen público de Seguridad Social para todos los ciudadanos, que garantice la asistencia y prestaciones sociales suficientes ante situaciones de necesidad, especialmente en caso de desempleo. La asistencia y prestaciones complementarias serán libres". La Seguridad Social constituye pues un pilar esencial del Estado de Bienestar, regido por un sistema de solidaridad, destinado a la prevención y remedio de situaciones de necesidad y de riesgos personales, mediante prestaciones individualizadas y económicamente evaluables.

En este sentido, la seguridad social probablemente sea una de las mejores creaciones humanas, y, desde luego, uno de los mayores exponentes del denominado "Estado del bienestar" (García Murcia, 2017).

De la letra del propio artículo 41 de la CE se configura y garantiza "El derecho de los españoles a la Seguridad Social", que presupone la existencia de una compleja relación jurídica entre el sujeto incluido en el ámbito de aplicación de un régimen de seguridad social y la entidad que cubre los riesgos (Alonso y Tortuero, 2000), las prestaciones que son debidas a los sujetos protegidos, la obligación de reintegrar las prestaciones indebidas percibidas por estos; entre otros aspectos de importancia e interés.

Por su parte, el artículo 42 de la Ley General de Seguridad Social $(\text { LGSS })^{1}$ pone de manifiesto que la acción protectora de la Seguridad Social, comprende además de la asistencia sanitaria, determinadas prestaciones económicas (invalidez, jubilación, desempleo, incapacidad temporal, muerte y supervivencia, así como también prestaciones familiares) que otorga en dos modalidades: la contributiva y la

1 Texto Refundido aprobado por Real Decreto Legislativo 8/2015, de 30 de octubre

(C) UNED. Revista de Derecho UNED, núm. 26, 2020 
no contributiva o asistencial; siendo la segunda modalidad, esto es, las prestaciones no contributivas, el objeto de estudio del presente trabajo, puesto en relación, básicamente, con el procedimiento de reintegro de prestaciones indebidas en la Comunidad Autónoma de Andalucía.

Al respecto, vale diferenciar las prestaciones contributivas de las no contributivas, puesto que las primeras vinculan su reconocimiento a la existencia de periodos previos de actividad profesional cotizada; mientras que las segundas supeditan su existencia a un estado de necesidad conectado con la ausencia de rentas suficientes en la unidad familiar del solicitante. De esta manera, nos encontramos con que ambos tipos de prestaciones tienen fuentes de financiación diferenciadas: las contributivas lo son con cargo a las cotizaciones de empresarios y trabajadores, mientras que las no contributivas son a cargo de los Presupuestos Generales del Estado.

Es importante señalar el hecho de que en la actualidad, la gestión y financiación de la asistencia sanitaria ha sido transferida a las Comunidades Autónomas, manteniendo el Estado sólo competencias generales relativas a la coordinación de los distintos sistemas autonómicos de salud, produciéndose algunas situaciones de falta de asistencia médica, salvo urgencias, cuando se presta la atención en distinta Comunidad Autónoma a la de residencia habitual.

$\mathrm{Y}$ en lo que atañe a este estudio se debe resaltar que en el supuesto de que se perciban indebidamente prestaciones, nace la obligación de restituirlas a la Administración. En este sentido el artículo 55 de la Ley General de la S. Social establece que los trabajadores y demás personas que hayan percibido indebidamente prestaciones de la Seguridad Social, vendrán obligados a reintegrar su importe $\mathrm{y}$, asimismo, quienes hayan contribuido a hacer posible la percepción indebida de una prestación, responderán subsidiariamente con los perceptores, salvo buena fe probada. El reintegro prescribe a los cuatro años contados a partir de la fecha de cobro o desde que fuera posible ejercitar la acción para exigir su devolución y deberá realizarse de conformidad con el procedimiento establecido en la propia Ley, como bien indica el artículo 45.2 del texto legal citado, en cuanto a la exigencia de responsabilidades.

Se pretende en este trabajo abordar los aspectos antes referenciados, dividiendo el estudio en tres capítulos, donde en el primero se tratan las generalidades de las Comunidades Autónomas a los fines de verificar la estructura política en España; el segundo capítulo se refiere a las pensiones no contributivas en la Comunidad Autónoma 
de Andalucía; y, por último, el capítulo tercero describe el procedimiento para el reintegro de prestaciones indebidamente percibidas.

\section{OBJETIVOS DE LA INVESTIGACIÓN.}

Como objetivo general del presente estudio, se menciona la descripción del procedimiento de reintegro de prestaciones indebidas, con énfasis en las PNC de la Comunidad Autónoma andaluza, desprendiéndose del objetivo general tres (3) objetivos específicos, a saber :

1. Conocer los aspectos generales de las Comunidades Autónomas de España.

2. Conceptualizar las PNC en la Comunidad Autónoma de Andalucía.

3. Señalar el procedimiento aplicable para el reintegro de prestaciones indebidas.

Tales objetivos, se han diseñado con el fin de dar respuesta al título del presente estudio, donde se pretende dar a conocer cuál es el papel que desempeñan en materia de seguridad social las Comunidades Autónomas en España, qué clase de pensiones no contributivas se encuentran vigentes en la CAA y cuál es el procedimiento para reintegrar prestaciones indebidas. Todo ello enmarcado en el ordenamiento jurídico español y en las disposiciones legislativas conexas de las propias CCAA.

\section{GENERALIDADES DE LAS COMUNIDADES AUTÓNOMAS.}

Políticamente España se estructura en Comunidades Autónomas de acuerdo con lo que establece la Constitución Española (CE) de 1978, hoy vigente, en cuyo artículo 2 dice que “.....reconoce y garantiza el derecho a la autonomía de las nacionalidades y regiones que la integran...", precepto que a su vez afirma la Unidad de la Nación española y el derecho a la autonomía. Es por ello, que el propio texto de la CE establece genéricamente las "competencias" que pueden ser asumidas por las comunidades autónomas, mediante la aprobación de sus Estatutos de Autonomía, dotándolas además de sus propios órganos de gobierno e instituciones representativas. La división política y administrativa de España adopta la forma de dieciséis (16) Comunidades Autónomas y una Comunidad Foral, la de 
Navarra, que ha sido equiparada en base a jurisprudencia del Tribunal Constitucional, con idéntico estatus que el resto de las comunidades autónomas.

Se puede decir en cuanto a Andalucía, que es una comunidad autónoma constituida en 30/12/1981, donde el proceso de autonomía política se llevó a cabo a través del procedimiento restrictivo expresado en el propio artículo 151 de la CE, lo que hace de Andalucía la única comunidad española que accedió a la autonomía a través de dicho procedimiento. La Comunidad Autónoma de Andalucía tiene reconocimiento como nacionalidad histórica en el vigente Estatuto de Autonomía ${ }^{2}$ y está integrada por las provincias de Almería, Cádiz, Córdoba, Granada, Huelva, Jaén, Málaga y Sevilla, siendo ésta última la sede del Parlamento y del Consejo de Gobierno de la Junta de Andalucía.

Andalucía en cuanto Comunidad Autónoma tiene su propio Tribunal de Cuentas, Defensor del Pueblo, Consejo Consultivo y otros organismos para su buen funcionamiento, siendo Granada la sede del Consejo Consultivo y del Tribunal Superior de Justicia de Andalucía.

La CE enumera los poderes y competencias de las Comunidades Autónomas, reservándose el Estado ciertas áreas sobre las que tiene competencias exclusivas, como se describen en el artículo 149 de la $\mathrm{CE}$ y algunas otras que son compartidas ${ }^{3}$. A las Comunidades Autónomas les han sido cedidas competencias en materia de educación, sistema de salud, cultura y lengua, patrimonio, asistencia social, ordenación del territorio y urbanismo, protección del medio ambiente, transporte público, agricultura, entre otras. Las competencias transferidas van a depender en gran medida de los respectivos Estatutos de Autonomía y pueden variar considerablemente de una comunidad autónoma a otra.

2 Estatuto de Autonomía de Andalucía. Artículo 1: “Andalucía, como nacionalidad histórica y en el ejercicio del derecho de autogobierno que reconoce la Constitución, se constituye en Comunidad Autónoma en el marco de la unidad de la nación española y conforme al artículo 2 de la Constitución.”. Boletín Oficial del Estado n. 68 de 20 de marzo de 2007, página 11872.

3 Título VIII. De la Organización Territorial del Estado - Constitución Española.www.congreso.es. Consultado el 27 de febrero de 2019. 


\subsection{Presupuesto y Distribución de Rentas de las Comunidades Autónomas.}

Los artículos 156 al 158 de la CE, determinan los aspectos básicos de la financiación de las CCAA, con la finalidad de crear un sistema que garantice la obtención de los recursos necesarios para ejercer las competencias que estas administraciones territoriales han ido asumiendo. En tal sentido, se establecen los siguientes principios:

- Autonomía financiera (aunque no de forma absoluta), donde se otorga cierta libertad a las Comunidades para decidir sobre sus gastos e ingresos.

- Solidaridad, para que exista un equilibrio económico adecuado y justo entre las diversas partes del territorio.

- Igualdad, a los efectos de impedir que las diferencias entre Estatutos impliquen privilegios económicos o sociales.

- Coordinación con la Hacienda Estatal, como garantía de eficacia del funcionamiento del conjunto del Estado Autonómico.

Pese a estos principios comunes no existe un modelo único para lograr la autonomía financiera, pues la mayoría de las Comunidades se rigen por el régimen común, previsto en la Ley Orgánica 8/1980, de 22 de septiembre, de Financiación de las Comunidades Autónomas (LOFCA) el País Vasco existe un sistema de Convenio y Concierto reconocido históricamente por la Constitución.

\section{LAS PENSIONES NO CONTRIBUTIVAS EN LA COMUNIDAD AUTÓNOMA DE ANDALUCÍA.}

Las prestaciones pueden definirse como aquellas atribuciones patrimoniales, en dinero o en especie, destinadas a cubrir estados de necesidad (Almansa, 1984) y también se definen como cada uno de los derechos o beneficios que a los asegurados o favorecidos indirectos se les concede en diferentes seguros sociales (Cabanellas, 2001), y en tal sentido, las prestaciones pueden consistir en : a) indemnizaciones en dinero; b) resarcimiento en especie; c) en un servicio,

4 BOE núm. 236 de 01 octubre de 1980 
y respecto de las pensiones no contributivas este autor señala lo siguiente :

"la pensión no contributiva es aquella suma de dinero mensual, prevista en disposiciones legislativas, de mayor o menor generalidad, asignan a personas que requieren tales prestaciones por razones de edad y otra causa que emplace a la obtención de recursos por ellas mismas para su subsistencia, y con exclusión de todo aporte previo para formar los fondos con que se atenderán estos desembolsos".-

Es destacable en este caso, y eso es lo que distingue a este tipo de pensión, la circunstancia de no haber aportado fondos para ese destino, esto es, no haber realizado cotización o haberlo hecho en forma insuficiente para lucrar una pensión. No obstante, la pensión no contributiva asegura una prestación de carácter económico de cuantía determinada, asistencia médico-farmacéutica y servicios sociales complementarios.

Para la Consejería de Igualdad y Políticas Sociales de la Comunidad Autónoma de Andalucía, las pensiones no contributivas (PNC) han reparado determinados espacios de justicia social, atendiendo a personas en estado de necesidad que por no haber cotizado nunca al Sistema de Seguridad Social o haberlo hecho por tiempo insuficiente para causar derecho a la pensión contributiva, carecen, además, de rentas o ingresos mínimos para su subsistencia.

Por tanto, la gestión y reconocimiento del derecho a percibir una PNC, se realiza por las Comunidades Autónomas, debido a que tienen transferidas las funciones y servicios del Instituto de Mayores y Servicios Sociales (IMSERSO). En el caso de Andalucía, la gestión corre a cargo de la Consejería de Igualdad, Políticas Sociales y Conciliación.

La normativa básica de estas prestaciones se encuentra en el Real Decreto 357/1991, de 15 de marzo, que desarrolla en materia de pensiones no contributivas la Ley 26/1990, de 20 de diciembre, por la que se establecen dentro del Sistema de la Seguridad Social, las prestaciones no contributivas, junto al Real Decreto 771/1997, de 30 de mayo, por el que se establecen reglas de determinación de los importes de las pagas extraordinarias de las pensiones de la Seguridad Social y el Real Decreto 1191/2012, de 3 de agosto, por el que se establecen normas para el reconocimiento del complemento de pensión para el alquiler de vivienda a favor de pensionistas de una PNC. 
Se debe indicar que existen dos tipos de PNC: 1.-) de jubilación, 2.-) de invalidez, que se concretan en ambos casos en una prestación económica; el derecho a la asistencia médico-farmacéutica gratuita y a los servicios sociales complementarios. La cobertura económica o prestación se determina anualmente por la Ley de Presupuestos Generales del Estado.

\subsection{Beneficiarios.}

Tienen derecho al percibo de las PNC tanto las personas de nacionalidad y residencia españolas, como las nacionales de otros países que tengan residencia legal en España, siendo por tanto beneficiarias de estas prestaciones. Es destacable el hecho de que muchos de estos beneficiarios son mujeres que han trabajado toda su vida sin ningún reconocimiento social o económico, como ocurre en la mayoría de zonas rurales. En consecuencia, las personas que obtienen el derecho a estas PNC se convierten en pensionistas de la Seguridad Social con las mismas garantías y los mismos beneficios que el resto de pensionistas el sistema, recibiendo:

— Una prestación económica mensual.

- Asistencia sanitaria y médico-farmacéutica gratuita

- Servicios Sociales y Ayudas complementarias

\subsection{Requisitos.}

Para el caso de las PNC que se otorgan en la CAA, los requisitos son de dos categorías a) de carácter general y b) de carácter específico. Siendo el requisito general que la persona carezca de ingresos suficientes, pudiendo originarse esta condición por las siguientes situaciones:

- Para el año 2018 en la CAA, la cuantía máxima anual de la PNC fue de 5.321,40 euros; en tal sentido, si la persona vivía sola y sus rentas o ingresos computables de las que se disponía eran inferiores a la cuantía máxima anual indicada, el criterio a aplicar era que esa persona podía obtener una PNC por carecer de ingresos.

- Por el contrario, si la persona convivía con familiares, en este supuesto se atiende al grado de parentesco de los familiares 
con los que conviva, el número de ellos y el volumen de rentas o ingresos totales de la unidad económica de convivencia (UEC), a los fines de determinar si puede o no ser beneficiaria de la PNC.

Adicionalmente, se consideran también los requisitos de carácter específico, los cuales se asocian a situaciones de: jubilación e invalidez. Para la obtención de una PNC de jubilación deben cumplirse con los siguientes requisitos:

- Es necesario que el/la solicitante en el momento de la solicitud, haya cumplido los 65 años de edad.

- El/la solicitante debe residir en territorio español o en el territorio de algún país miembro de la Unión Europea durante 10 años; para este caso, debe considerarse el periodo que media entre la fecha en que la persona solicitante hubiese cumplido los 16 años y la de devengo de la pensión, dos de los cuales han de ser consecutivos e inmediatamente anteriores a la fecha de solicitud.

Por último, para el caso de las PNC por causa de invalidez, sus requisitos son los siguientes:

- Para la fecha de la solicitud, la persona debe ser mayor de 18 años y menor de 65 años de edad.

- Residir en el territorio español o en el territorio de algún país miembro de la UE durante un periodo de 5 años, de los que 2 han de ser consecutivos e inmediatamente anteriores a la fecha de presentación de la solicitud.

- La persona solicitante debe estar afectada por una discapacidad o por una enfermedad crónica, en un grado igual o superior al $65 \%$.

- En los casos de presentar un grado de discapacidad igual o mayor al 75\% y se acredite la necesidad del concurso de otra persona, mediante la superación del baremo establecido, se percibirá un complemento del $50 \%$ del importe máximo anual.

El vigente artículo 367.3 del Real Decreto Legislativo 8/2015, de 30 de octubre, por el que se aprueba el Texto Refundido de la Ley General de la Seguridad Social, establece que "Las pensiones de in- 
validez no contributivas, cuando sus beneficiarios cumplan la edad de sesenta y cinco años, pasarán a denominarse pensiones de jubilación. La nueva denominación no implicará modificación alguna respecto a las condiciones de la prestación que viniesen percibiendo". Por tal razón, el beneficiario de este tipo de PNC no tiene que realizar ninguna actuación y continuará percibiendo la prestación siempre y cuando mantenga los requisitos de recursos y de residencia legal, ya que la discapacidad no le será revisada a estos efectos.

\subsection{Cómputo de Ingresos.}

Los recursos computables incluyen todos los ingresos percibidos por la persona solicitante y por los familiares que convivan en la unidad económica de convivencia (UEC) en el año de la solicitud; por lo tanto, a los fines del otorgamiento de la PNC, se consideran rentas o ingresos computables los bienes y derechos de que dispongan anualmente la persona beneficiaria o la UEC, derivados tanto del trabajo como del capital, así como cualesquiera otros sustitutivos de aquellos, computándose por su importe íntegro o bruto. No obstante, se excluyen como parte de tales ingresos computables, los siguientes:

- Prestación económica por hijo a cargo, con o sin condición de persona con discapacidad.

- Las deducciones fiscales de pago directo por hijos menores a cargo.

- El subsidio de movilidad y compensación para gastos de transporte.

- Premios o recompensas otorgadas a personas con discapacidad en los centros ocupacionales.

- Subvenciones, ayudas o becas destinadas a compensar un gasto realizado.

- Las prestaciones económicas y en especie otorgadas al amparo de la Ley 39/2006, de 14 de diciembre, de promoción de la autonomía personal y atención a las personas en situación de dependencia.

- Ayudas sociales para mujeres víctimas de violencia de género reguladas por el Real Decreto 1452/2005, de 2 de diciembre, en virtud del art. 27 de la Ley Orgánica 1/2004, de 28 de di- 
ciembre, de Medidas de Protección Integral contra la Violencia de Género.

Por otra parte, a las personas beneficiarias de la PNC de invalidez que inicien actividad laboral por cuenta propia o ajena, les serán de aplicación el Real Decreto Legislativo 8/2015 de 30 de octubre, para compatibilizar dicha pensión con el trabajo remunerado. No se les tendrán en cuenta en el cómputo anual de rentas propias las que hubiera percibido en virtud de su trabajo y/o subsidios por desempleo, en el ejercicio en que se reponga el pago de la pensión.

Por consiguiente, la pensión es compatible con cualquier otra prestación, ayuda o subsidio, con la obligación de declarar en un plazo máximo de 30 días los ingresos percibidos por estos conceptos, a efectos del cálculo de los ingresos económicos de la unidad económica de convivencia, para la determinación del derecho a la pensión y, en su caso, para la determinación de la cuantía, dando lugar, en otro caso, al procedimiento de reintegro por estimarse como indebidamente percibida la prestación.

\subsection{Cuantía y límites.}

Las PNC de jubilación e invalidez se financian con cargo al Presupuesto del Estado para la Seguridad Social, figurando el crédito en el presupuesto del Instituto de Mayores y Servicios Sociales, y abonándose las pensiones a través de la Tesorería General de la Seguridad Social. El importe básico anual se fija en la Ley de Presupuestos Generales del Estado, distribuyéndose en 12 mensualidades más dos pagas extraordinarias, y señala también las cuantías máxima y mínima de la PNC, con arreglo a los siguientes criterios : a) para establecer la cuantía de la pensión para cada persona beneficiaria se fija en función de sus ingresos y rentas personales. b) en los casos de los miembros que convivan en su UEC, la PNC no puede ser inferior a la cuantía mínima, ni superior a la cuantía máxima, igualmente en cómputo anual.

La cuantía individual de cada beneficiario se determina en base a la cuantía básica indicada y en función del número de beneficiarios de PNC integrados en la misma unidad económica de convivencia y de los recursos de que dispongan el interesado y/o las personas que componen dicha unidad económica de convivencia.

En la CAA se estableció para el Ejercicio 2019 la actualización y revalorización de las PNC del 3\%, en relación al ejercicio 2018, se- 
gún establece el Real Decreto-ley 28/2018, de 28 de diciembre, para la revalorización de las pensiones públicas y otras medidas urgentes en materia social, laboral y de empleo. Para el año 2020 se aplicó la revalorización del 0.9\%, prevista en el Real Decreto-Ley 1/2020, de 14 de enero, siendo los importes vigentes de las PNC de jubilación e invalidez los que se recogen en los cuadros siguientes:

\section{Pensiones de Jubilación e Invalidez Año 2020}

\section{$n^{o}$ 1.- Cuantías por número de Convivientes}

\begin{tabular}{lcc}
\hline & $\begin{array}{c}\text { NÚMERO DE } \\
\text { CONVIVIENTES }\end{array}$ & EUROS/AÑo \\
\hline $\begin{array}{l}\text { Si convive sólo con su cónyuge y/o } \\
\text { parientes consanguíneos de segundo } \\
\text { grado (hermano-hermana, nieto-nieta o } \\
\text { abuelo-abuela) }\end{array}$ & 2 & $9.415 .28 €$ \\
\cline { 2 - 3 } & 3 & $13.292 .16 €$ \\
\cline { 2 - 3 } $\begin{array}{l}\text { Si entre los parientes consanguíneos } \\
\text { con los que convive se encuentra alguno } \\
\text { de primer grado (padres y madres o hijos }\end{array}$ & 4 & $17.169 .04 €$ \\
\cline { 2 - 3 } e hijas) & 2 & $21.045 .92 €$ \\
\cline { 2 - 3 } & 5 & $23.538 .20 €$ \\
\hline
\end{tabular}

Fuente: https://www.juntadeandalucia.es/organismos/igualdadpoliticassocialesyconciliacion/areas/pensiones/pensiones-no-contributivas.html

$$
\text { no } 2 \text {.- Cuantías Básicas }
$$

\begin{tabular}{lccc}
\hline & ANUAL & MENSUAL & N PAGAS $^{\circ}$ \\
\hline $\begin{array}{l}\text { Cuantía Máxima 1 } \\
\text { Beneficiario }\end{array}$ & $5.538 .40 €$ & $395.60 €$ & 14 \\
\hline $\begin{array}{l}\text { Cuantía Mínima: }(25 \% \text { de la } \\
\text { máxima) }\end{array}$ & $1.384 .60 €$ & $98,90 €$ & 14 \\
\hline $\begin{array}{l}\text { Invalidez: Complemento } \\
(50 \% \text { de la Máxima) }\end{array}$ & $2.769 .20 €$ & $197.80 €$ & 14 \\
\hline $\begin{array}{l}\text { Integra Invalidez: } \\
\text { Complemento (50\% de la } \\
\text { Máxima) }\end{array}$ & $8.307 .60 €$ & $593,00 €$ & 14 \\
\hline
\end{tabular}

Fuente: https:/www.juntadeandalucia.es/organismos/igualdadpoliticassocialesyconciliacion/areas/pensiones/pensiones-no-contributivas.html 
$n^{\circ}$ 3.- Importe máximo anual con más de un beneficiario en la UEC

En caso de convivir dos o más personas beneficiarias/titulares de PNC dentro de la misma UEC el importe máximo anual de la pensión para cada uno es el que se indica a continuación:

\begin{tabular}{cccc}
\hline & ANUAL & MENSUAL & N $^{\mathbf{0}}$ PAGAS \\
\hline 2 Titulares & $4.707 .64 €$ & $336.26 €$ & 14 \\
\hline 3 Titulares & $4.430 .72 €$ & $316.48 €$ & 14 \\
\hline 4 Titulares & $4.292 .26 €$ & $306.59 €$ & 14 \\
\hline 5 Titulares & $4.209 .18 €$ & $300.66 €$ & 14 \\
\hline
\end{tabular}

Fuente: https://www.juntadeandalucia.es/organismos/igualdadpoliticassocialesyconciliacion/areas/pensiones/pensiones-no-contributivas.html

\subsection{Obligaciones de los beneficiarios.}

Los perceptores de las pensiones de invalidez y jubilación en la modalidad de PNC, estarán obligados a comunicar, en el plazo máximo de 30 días desde la fecha en que se produzca, cualquier variación de su situación de convivencia, tales como: estado civil, residencia, recursos económicos propios o ajenos computables por razón de convivencia, baja de algún miembro de la UEC (por traslado de domicilio, fallecimiento, etc.), variación en los ingresos de la UEC, fallecimiento de la persona beneficiaria y cualquier otra circunstancia que pudiera tener incidencia en la PNC.

En tal sentido, cuando la persona beneficiaria de una PNC perciba una prestación de Renta Activa de Inserción (RAI), deberá comunicarlo de forma inmediata a la Delegación Territorial de la Consejería de Igualdad y Políticas Sociales de su provincia, ya que mientras dure la percepción de la RAI, se le deberá suspender del derecho de la PNC y a la asistencia sanitaria y farmacéutica gratuitas. No comunicarlo, genera de inmediato la obligación de reintegrar las cantidades indebidamente percibidas.

Por otra parte, las personas beneficiarias de las PNC están obligadas a presentar una Declaración Anual (en el primer trimestre de cada año) de los ingresos o rentas computables de toda la UEC, referidos al año inmediato anterior. Al mismo tiempo, declararán las posibles variaciones en los ingresos o rentas justificados, referidos al año en curso. En caso de incumplimiento de dicha obligación, y previo requerimiento del organismo gestor a la persona beneficiaria, con 
la advertencia expresa de las consecuencias del incumplimiento, se procederá, como medida cautelar, a suspender el pago de la pensión.

\subsection{Prestaciones Devengadas y No Percibidas.}

En el supuesto de fallecimiento del solicitante o beneficiario de PNC, sus herederos podrán solicitar las cuantías devengadas y no percibidas por el interesado. En estos casos deberá presentarse conjuntamente con la solicitud debidamente cumplimentada; certificado de defunción, número de cuenta bancaria en la que figure como titular el solicitante de la prestación devengada y no percibida, copia del DNI del solicitante de la prestación devengada o autorización para consulta de ficheros, copia del libro de familia, copia autorizada del testamento o, en el caso de no haberlo otorgado, certificado de últimas voluntades.

\subsection{Extinción del Derecho y Renuncia a la Pensión no Contributiva.}

Cuando concurra alguna de las siguientes circunstancias, se producirá la extinción del derecho a la PNC:

a. Pérdida de la condición de residente legal o traslado de la residencia fuera del territorio español por tiempo superior a noventa días.

b. Disponer de rentas o ingresos suficientes, es decir, superar los límites de acumulación de recursos fijados para cada caso.

c. En el caso de las PNC de invalidez, la mejoría de la discapacidad o enfermedad crónica padecida que determine un grado inferior al 65 por 100 .

d. Fallecimiento de la persona beneficiaria.

Se ha de indicar también, que el derecho al reconocimiento de las PNC es irrenunciable de acuerdo con lo que dispone el artículo 3 del TRLG de Seguridad Social que dice : "Será nulo todo pacto, individual o colectivo, por el cual el trabajador renuncie a los derechos que le confiere la presente ley". Sin embargo, se admite la renuncia a la PNC en el caso de cuantía mínima a efectos de acceder al complemento por cónyuge a cargo, siempre que ello sea más ventajoso, económicamente, para la unidad familiar. 
Cuando se produce cualquiera de las mencionadas circunstancias, nace de inmediato la obligación de reintegro o devolución de lo que resulte indebidamente percibido, siendo los motivos más habituales la falta de comunicación en tiempo hábil del fallecimiento del beneficiario, lo que provoca se sigan efectuando ingresos mensuales en la cuenta bancaria donde se halle domiciliada la prestación, y la variación de rentas producida dentro del seno de la UEC, cuando alguno o más de un miembro de dicha unidad perciba rentas o ingresos que superen los límites inicialmente establecidos.

\section{PROCEDIMIENTO DE REINTEGRO DE PRESTACIONES INDEBIDAMENTE PERCIBIDAS.}

La obligación de reintegro, para trabajadores y demás personas, que hayan percibido indebidamente prestaciones de la Seguridad Social, se encuentra establecida en el artículo 55 del TR de la Ley General de la Seguridad Social (RDLeg. 8/2015), y el procedimiento especial para el reintegro de las prestaciones de la Seguridad Social indebidamente percibidas, está regulado en el Real Decreto $359 / 2009$, de 20 de marzo, y en aquellos casos en que no pueda ser aplicado, lo será de manera supletoria por el contenido del artículo 80 del Real Decreto 1415/2004, de 11 de junio, que aprueba el Reglamento General de Recaudación de la S. Social.

\subsection{Derecho de la Tesorería General de la S. Social a obtener el reintegro de los ingresos abonados indebidamente.}

Si como consecuencia del incumplimiento de alguna de las obligaciones por parte del beneficiario de una PNC, se derivara una percepción indebida de prestaciones, la persona beneficiaria deberá reintegrar las cantidades indebidamente percibidas desde el primer día del mes siguiente a aquel en que hubiera variado la situación, cualquiera que sea el momento en que se detecte la misma, salvo que la acción para solicitar la devolución hubiera prescrito.

De modo que la persona beneficiaria de una PNC no debe esperar a la revisión anual para comunicar aquellas variaciones que puedan afectar a la cuantía de la pensión, evitando de esta forma las posibles reclamaciones de cantidades percibidas indebidamente.

De acuerdo con al Artículo 31.3 del Real Decreto Legislativo $8 / 2015$, del 30 de octubre, las devoluciones de ingresos indebidos in- 
cluirán el interés de demora desde la fecha de su ingreso en la Tesorería General de la Seguridad Social hasta la fecha de la propuesta de pago, sin que proceda la devolución de cuotas u otros recursos que hayan sido ingresados maliciosamente, sin perjuicio de la responsabilidad de todo orden a que hubiera lugar.

Los ingresos que, en virtud de resolución judicial firme, resulten o se declaren objeto de devolución por los interesados tendrán la consideración de ingresos indebidos y serán objeto de devolución en los términos fijados en dicha resolución (art. 106, Ley 29/1998, de 13 de julio), cuando la Administración de la Seguridad Social fuera condenada al pago de una cantidad líquida, o de lo dispuesto en la Ley General Presupuestaria, en otro caso.

El derecho a la devolución de ingresos indebidos de cuotas prescribirá a los cuatro años, a contar desde el día siguiente a su ingreso. Una vez reconocida la procedencia de la devolución, el derecho a exigir su pago caducará a los cuatro años a contar desde la fecha de notificación del acto de reconocimiento. En este sentido, las sentencias del TSJ Castilla-La Mancha, de 20/01/2000 y TSJ Madrid, de 20/07/1999, han sentado el criterio de que el derecho a la devolución de ingresos indebidos de cuotas prescribirá a los cuatro años, a contar desde el día siguiente a su ingreso. Una vez reconocida la procedencia de la devolución, el derecho a exigir su pago caducará a los cuatro años a contar desde la fecha de notificación del acto de reconocimiento.

En tal sentido, las Sentencias del Tribunal Supremo-Sala $4^{\mathrm{a}}$ de lo Social- de fecha 16/02/2016 dictadas en los Recursos 1931/2014 y 2938/2014, en relación con la obligación de reintegro del importe de las prestaciones indebidamente percibidas, considera que el plazo de prescripción de cuatro años comienza a correr desde la fecha de emisión del Acta de la Inspección de Trabajo.

El derecho a la devolución de ingresos distintos de cuotas o demás conceptos de recaudación conjunta y asimilados a aquéllas se sujetará a los plazos de prescripción establecidos en las normas aplicables a la naturaleza de tales recursos.

Serán a cargo de la Entidad Gestora o Colaboradora por cuya cuenta se efectúe la devolución de ingresos indebidos los intereses de demora que se satisfagan a los interesados, el importe del reembolso de los costes de las garantías aportadas para suspender el procedimiento de recaudación y los intereses que procedan sobre éste. 
Como indica el artículo 55 de la LGSS, ya citado, la obligación de reintegro de los trabajadores y demás personas que hubieran percibido indebidamente prestaciones de la Seguridad Social, tienen obligación de reintegrar quienes por acción u omisión contribuyeran a hacer posible la percepción indebida de una prestación, deben responder subsidiariamente con los perceptores, salvo que se acredite buena fe probada, sin perjuicio de la exigencia de la responsabilidad administrativa o penal que legalmente correspondiera a aquéllos. La obligación de reintegro del importe de las prestaciones indebidamente percibidas prescribiría a los cuatro años, contados a partir de la fecha de su cobro, o desde que fue posible ejercitar la acción para exigir su devolución, con independencia de la causa que originó la percepción indebida, incluidos los supuestos de revisión de las prestaciones por error imputable a la entidad gestora.

\subsection{Competencia y plazo de resolución.}

En primer lugar, le corresponde a la Tesorería General de la Seguridad Social, conforme a la distribución de competencias que ésta tenga establecida, resolver sobre la procedencia de la devolución de las cantidades ingresadas indebidamente. Será entonces la Tesorería General de la Seguridad Social quien resolverá las solicitudes presentadas o las remitirá, cuando proceda, al organismo correspondiente junto a la documentación presentada para la adopción de la resolución procedente.

En segundo término, corresponderá la resolución a los órganos u organismos gestores, en el supuesto de que la devolución se refiera a los conceptos de recaudación conjunta con las cuotas. En este caso, estos órganos comunicarán a la Tesorería General de la Seguridad Social sus resoluciones, una vez sean firmes en vía administrativa.

En aquellos otros casos donde la devolución se solicite como consecuencia de errores materiales o de cálculo, por duplicidades de ingreso o por exceso sobre el tope máximo absoluto de la base de cotización, por períodos posteriores a la fecha de efectos de la baja o después de haber prescrito la acción para exigir su pago, o en cualquier supuesto en que la resolución de devolución deba basarse exclusivamente en la comprobación material, aritmética o contable o en el simple cómputo de los extremos alegados por los interesados, no se requerirá resolución previa de los aludidos órganos u organismos gestores. 
En cualquier caso, la resolución deberá adoptarse y notificarse dentro de los seis meses siguientes a la fecha en que se hubiera completado la documentación que deba aportar el solicitante de la devolución. Transcurrido dicho plazo sin que haya recaído resolución expresa, podrá entenderse desestimada la solicitud.

\subsection{Reglas de procedimiento de reintegro.}

El Real Decreto 148/1996, de 5 de febrero, regula el procedimiento especial para el reintegro de las prestaciones de la Seguridad Social indebidamente percibidas. El procedimiento se inicia, por acuerdo de la entidad gestora o colaboradora, administración u organismo público correspondiente, tan pronto tenga conocimiento de los hechos o circunstancias que evidencien la existencia de deudas de tal naturaleza, tramitándose en un solo expediente que debe resolverse en el plazo máximo de tres meses, contados a partir de la fecha del mencionado acuerdo que debe ser notificado al interesado.

Como indica la normativa vigente, la entidad gestora, debe dar audiencia al interesado antes de redactar la propuesta de resolución, con la finalidad de informarle acerca de las actuaciones practicadas y los hechos o datos conocidos y consecuencias que de ellos se deriven, para que de esta manera el sujeto responsable pueda presentar las alegaciones o documentos que estime conveniente.

A estos efectos, la entidad gestora o colaboradora, administración u organismo remitirá a la Tesorería General de la Seguridad Social las citadas resoluciones o acuerdos firmes en vía administrativa, con indicación del momento en que se hubiese realizado su notificación al sujeto responsable y de si han sido o no impugnadas ante los tribunales.

De igual manera, en caso de ser procedente de conformidad al artículo 4 del RD 148/1996, de 5 de febrero, se efectuará propuesta de reintegro de la deuda, sobre determinación de descuentos, a fin de que el interesado manifieste su conformidad o formule propuestas alternativas; siempre que de las mismas resulten unas cuantías superiores a las que se derivan de las mencionadas reglas. Para ello, se concederá al interesado un plazo de 15 días, contados a partir del día siguiente a aquel en que tenga lugar la notificación.

Recibidas las alegaciones o documentos del interesado o transcurrido el plazo concedido sin que éste se manifieste, se dictará la resolución que corresponda a la vista de todos los datos obrantes en 
el expediente, que será motivada y hará mención expresa de los siguientes extremos:

- Determinación de las causas que han motivado la deuda, con la indicación del período al que ésta se refiere y su cuantía.

- Fijación, en su caso, de la nueva cuantía de la prestación que corresponda percibir y fecha de efectos económicos.

- Procedencia del reintegro de las cantidades indebidamente percibidas, especificando el procedimiento para hacerlo efectivo y, en su caso, determinación del importe y plazo del descuento.

- Plazo y órgano ante el que puede interponerse reclamación previa.

La entidad gestora al notificar la resolución, debe también informar al deudor sobre la posibilidad de abonar de manera voluntaria el importe íntegro de la deuda en un solo plazo, dentro de los treinta días siguientes al de dicha notificación, suministrando incluso los formularios propios para efectuar dicho ingreso.

Transcurrido el plazo señalado sin que el deudor acredite haber efectuado el pago de la deuda, mediante el correspondiente recibo justificativo del mismo, se aplicarán los descuentos fijados en la resolución de la entidad gestora.

Para el reintegro de las citadas prestaciones, la Tesorería General de la Seguridad Social expedirá reclamación de deuda en la que se fijará el plazo reglamentario para el reintegro, que comenzará con la notificación de dicha reclamación y finalizará el último día hábil del mes siguiente al de aquella notificación, pudiendo el sujeto obligado solicitar el establecimiento de diversos plazos reglamentarios para tal devolución.

Los órganos de la Tesorería General de la Seguridad Social, podrán establecer dichos plazos reglamentarios, hasta un máximo de cinco años, cuando la situación económica y demás circunstancias concurrentes, discrecionalmente apreciadas por el órgano competente para resolver, impidan efectuar el reintegro en el plazo indicado en la reclamación. En caso de denegación de la solicitud, la resolución dará un nuevo plazo de ingreso de 15 días desde la notificación de la resolución, salvo que fuere mayor la parte del plazo que reste para el pago fijado en la reclamación de deuda. 
En el supuesto de falta de ingreso en el plazo indicado en la reclamación de deuda o en la resolución denegatoria de la ampliación del plazo reglamentario de ingreso, se iniciará el procedimiento ejecutivo mediante la emisión de la correspondiente providencia de apremio.

Por otra parte, la falta de ingreso del importe correspondiente a alguno de los plazos reglamentarios concedidos, determinará la revocación de la autorización por la que se concedían dichos plazos, y se iniciará automáticamente la vía ejecutiva, mediante la emisión de la correspondiente providencia de apremio, por la totalidad del importe que quedara por pagar. En este caso, y a efectos de cálculo de los intereses de demora que correspondan, se entenderá como plazo reglamentario de ingreso, el primer plazo dejado de ingresar.

Las sentencias firmes en el orden jurisdiccional social que recaigan sobre las resoluciones o acuerdos firmes que declaren la obligación de devolver las prestaciones indebidamente percibidas, serán asimismo comunicados a la Tesorería General de la Seguridad Social, al objeto de continuar el procedimiento recaudatorio en los términos que procedan.

De conformidad al artículo 80 del Real Decreto 1415/2004 de 11 de Junio, que aprueba el Reglamento General de Recaudación de la Seguridad Social, los reintegros de prestaciones declarados por resolución judicial, sin que exista previamente resolución de la entidad gestora o colaboradora, administración u organismo público correspondiente, se efectuarán en los términos establecidos en ella, y en defecto de cumplimiento voluntario, se instará su ejecución judicial, a cuyos efectos deberá ser remitida a la Tesorería General de la Seguridad Social.

\subsection{Exclusión de la aplicación del procedimiento de reintegro.}

De conformidad a la Disposición Adicional 2a del RD 148/1996, de 5 de febrero, según redacción contenida en el RD 359/2009, de 20 de marzo, que regula el procedimiento especial para reintegro de las prestaciones de la Seguridad Social percibidas indebidamente, dispone que se regirá por sus normas específicas la compensación entre prestaciones por incapacidad temporal e invalidez permanente percibidas en períodos coincidentes y entre las de invalidez permanente en supuestos de revisión del grado de incapacidad. 
En el supuesto de falta de ingreso en el plazo indicado en la reclamación de deuda o en la resolución denegatoria de la ampliación del plazo reglamentario de ingreso, se iniciará el procedimiento ejecutivo mediante la emisión de la correspondiente providencia de apremio.

Por otra parte, la falta de ingreso del importe correspondiente a alguno de los plazos reglamentarios concedidos, determinará la revocación de la autorización por la que se concedían dichos plazos, y se iniciará automáticamente la vía ejecutiva, mediante la emisión de la correspondiente providencia de apremio, por la totalidad del importe que quedara por pagar. En este caso, y a efectos de cálculo de los intereses de demora que correspondan, se entenderá como plazo reglamentario de ingreso, el primer plazo dejado de ingresar.

Las sentencias firmes en el orden jurisdiccional social que recaigan sobre las resoluciones o acuerdos firmes que declaren la obligación de devolver las prestaciones indebidamente percibidas, serán asimismo comunicados a la Tesorería General de la Seguridad Social, al objeto de continuar el procedimiento recaudatorio en los términos que procedan.

De conformidad al artículo 80 del Real Decreto 1415/2004 de 11 de Junio, que aprueba el Reglamento General de Recaudación de la Seguridad Social, los reintegros de prestaciones declarados por resolución judicial, sin que exista previamente resolución de la entidad gestora o colaboradora, administración u organismo público correspondiente, se efectuarán en los términos establecidos en ella, y en defecto de cumplimiento voluntario, se instará su ejecución judicial, a cuyos efectos deberá ser remitida a la Tesorería General de la Seguridad Social.

\subsection{Exclusión de la aplicación del procedimiento de reintegro.}

De conformidad a la Disposición Adicional 2a del RD 148/1996, de 5 de febrero, según redacción contenida en el RD 359/2009, de 20 de marzo, que regula el procedimiento especial para reintegro de las prestaciones de la Seguridad Social percibidas indebidamente, dispone que se regirá por sus normas específicas la compensación entre prestaciones por incapacidad temporal e invalidez permanente percibidas en períodos coincidentes y entre las de invalidez permanente en supuestos de revisión del grado de incapacidad. 
De igual modo, sin perjuicio de lo dispuesto en la Disposición Adicional $3^{\mathrm{a}}$, quedan excluidas de la aplicación del procedimiento previsto en este Real Decreto las deudas por prestaciones por desempleo indebidamente percibidas, cuyo reintegro se regirá por sus normas específicas.

\subsection{Reintegro de prestaciones indebidas de PNC 2013-2018}

Los expedientes de reintegro de prestaciones indebidas son fundamentalmente de dos clases : los de Retrocesión por fallecidos, que se incoan al mes siguiente del óbito del pensionista, efectuando la reclamación a sus familiares, gracias a la colaboración del Registro Civil que comunica estas situaciones, con lo cual en la inmensa mayoría de las ocasiones lo abonado indebidamente no suele pasar de un mes, siendo por tanto más que un verdadero expediente de reintegro o devolución una retrocesión que es menos numerosa y por tanto con un impacto económico menor, teniendo una buena respuesta colaborativa tanto de familiares como de las entidades de ahorro y bancarias colaboradoras.

A la vista de los datos facilitados por la Dirección General de Personas Mayores y Pensiones no Contributivas, de la Consejería de Igualdad, Políticas Sociales y Conciliación de la Junta de Andalucía, relativos a los expedientes instruidos en el período 2013-2018, podemos observar que han ido en descenso conforme nos hemos ido alejando de la crisis iniciada en 2008, de tal modo que a partir del año 2015, que algunos señalan como el final de la recesión económica, las retrocesiones han ido en disminución hasta llegar al año 2018 con tan solo 250 expedientes para toda la Comunidad andaluza. La disminución de expedientes de retrocesión por fallecimiento implica un menor importe distraído y, en consecuencia, una mejor gestión y eliminación de posible fraude, evitando la dispersión de los recursos asignados para atender el pago de las prestaciones no contributivas, como se desprende de la siguiente Tabla :

$n^{\circ}$ 1.- Retrocesiones (Fallecidos) 2013-2018

\begin{tabular}{ccc}
\hline AÑO & EXPEDIENTES INSTRUIDOS & IMPORTE EUROS \\
\hline 2013 & 2.895 & 2.668 .065 .28 \\
\hline 2014 & 3.089 & 2.698 .060 .51 \\
\hline 2015 & 2.291 & 1.570 .269 .53 \\
\hline
\end{tabular}


EL REINTEGRO DE PRESTACIONES SOCIALES INDEBIDAS: EL CASO DE LAS...

\begin{tabular}{ccc}
\hline AÑO & EXPEDIENTES INSTRUIDOS & IMPORTE EUROS \\
\hline 2016 & 2.180 & 1.686 .886 .93 \\
\hline 2017 & 1.177 & 697.334 .95 \\
\hline 2018 & 250 & 404.030 .54 \\
\hline TOTALES & $\mathbf{1 1 . 8 8 2}$ & $\mathbf{9 . 7 4 4 . 6 4 7 , 7 4}$ \\
\hline
\end{tabular}

Fuente: Elaboración propia con datos facilitados por la Dirección General de Personas Mayores y Pensiones No Contributivas, de la Consejería de Igualdad, Políticas Sociales y Conciliación de la Junta de Andalucía.

De acuerdo con los datos expuestos, la media por expediente alcanza la cifra de 820,12 euros, equivalente al importe de dos mensualidades de PNC, lo que demuestra por un lado, eficacia y rapidez en la actuación del Departamento de Nóminas procediendo a la supresión del pago y por otra parte, agilidad en la reclamación y recuperación de lo satisfecho indebidamente.

La indicada tabla se complementa con la $\mathrm{N}^{\circ} 2$ siguiente, en la que aparecen todas las provincias que integran la Junta de Andalucía, ordenadas en razón del número de expedientes tramitados en cada uno de los ejercicios del período 2013-2018, siendo destacable y significativo que de las cuatro primeras provincias, es decir, la mitad del territorio, tres de ellas corresponden a provincias marítimas, como es el caso de Málaga, Cádiz y Almería. Curiosamente, Granada que tiene costa, encabeza la lista de las cuatro restantes provincias junto a Córdoba y Jaén, y sin embargo Huelva que siendo también marítima, es la que menos expedientes ha tramitado. Esta situación puede interpretarse como que la provincia de Málaga tiene un censo de pensionistas de PNC muy numeroso cuyo origen habrá que buscarlo en la longevidad de sus perceptores y también en el hecho de acceso a estas prestaciones de un elevado número de su población que ha carecido de cotizaciones suficientes para lucrar una pensión contributiva, lo que viene a poner de manifiesto que en esa provincia las aportaciones por cotizaciones empresariales y obreras han sido bajas respecto a la realidad laboral, es decir, se ha trabajado de forma irregular y en trabajos ocasionales, de temporada o corta duración, y en el sector servicios, principalmente turístico.

Sin embargo, Jaén y Huelva, son las dos Provincias que menos expedientes han tramitado en el período de observación, con una notable disminución conforme se han ido alejando del final de la crisis, es decir, de 2015 a 2018, siendo en este último año prácticamente testimoniales los 8 expedientes de Jaén y los 4 de Huelva. 
$n^{\circ}$ 2.- Expedientes de retrocesiones por provincias 2013-2018

\begin{tabular}{cccccccc}
\hline PROVINCIA & $\mathbf{2 0 1 3}$ & $\mathbf{2 0 1 4}$ & $\mathbf{2 0 1 5}$ & $\mathbf{2 0 1 6}$ & $\mathbf{2 0 1 7}$ & $\mathbf{2 0 1 8}$ & TOTALES \\
\hline MÁLAGA & 582 & 798 & 652 & 531 & 378 & 63 & 3.004 \\
\hline SEVILLA & 727 & 582 & 483 & 500 & 280 & 55 & 2.627 \\
\hline CÁDIZ & 506 & 533 & 298 & 282 & 147 & 43 & 1.809 \\
\hline ALMERÍA & 229 & 381 & 360 & 425 & 135 & 37 & 1.567 \\
\hline GRANADA & 286 & 240 & 192 & 151 & 74 & 35 & 978 \\
\hline CÓRDOBA & 241 & 214 & 93 & 110 & 63 & 5 & 726 \\
\hline JAEN & 190 & 181 & 91 & 75 & 42 & 8 & 587 \\
\hline HUELVA & 134 & 160 & 122 & 106 & 58 & 4 & 584 \\
\hline TOTALES & $\mathbf{2 . 8 9 5}$ & $\mathbf{3 . 0 8 9}$ & $\mathbf{2 . 2 9 1}$ & $\mathbf{2 . 1 8 0}$ & $\mathbf{1 . 1 7 7}$ & $\mathbf{2 5 0}$ & $\mathbf{1 1 . 8 8 2}$ \\
\hline
\end{tabular}

Fuente: Elaboración propia con datos facilitados por la Dirección General de Personas Mayores y Pensiones No Contributivas, de la Consejería de Igualdad, Políticas Sociales y Conciliación de la Junta de Andalucía

Por otro lado, examinando los expedientes de Reintegro de Prestaciones del período de observación 2013-2018, que se exponen en la Tabla $\mathrm{n}^{\circ} 3$, en los que ha intervenido una fiscalización y comprobación con cruce de datos, resulta que, evidentemente, son mucho más numerosos y vienen a representar una media de 2.332.05 euros por cada uno, equivalente a 5 mensualidades de PNC, lo cual nos proporciona la idea de que nos movemos en situaciones de abuso o fraude, sin despreciar posibles omisiones o errores incluso de la Administración, pero en general, responden a incumplimiento de condiciones generales para ser acreedores a la percepción de la PNC.

Debido a la protección de datos, no es posible contar con información más detallada acerca de la razón de la instrucción de estos expedientes, como por ejemplo, falsedades documentales, ocultación de ingresos, cambio de estado civil, modificación de la unidad de convivencia, suplantaciones, etc., que sin duda hubiera enriquecido este estudio.

Puede observarse que estos reintegros de prestaciones indebidamente satisfechas, no han experimentado una disminución tan notable como en el caso de las retrocesiones, conforme nos alejamos de la crisis, sino que manifiestan una continuidad, lo que nos lleva a pensar que la fiscalización y el control de las mismas, es deficitario e insuficiente, que debería revisarse y modificarse, imponiendo sanciones a más de la pérdida del derecho, sobre todo en los casos de fa- 
EL REINTEGRO DE PRESTACIONES SOCIALES INDEBIDAS: EL CASO DE LAS...

miliares que, con ocultamiento del fallecimiento del beneficiario, siguen percibiendo la prestación mediante su domiciliación bancaria.

n 3 .- Expedientes de reintegro de prestaciones 2013-2018

\begin{tabular}{ccc}
\hline AÑO & EXPEDIENTES INSTRUIDOS & IMPORTE RECUPERADO \\
\hline 2013 & 5.679 & 12.918 .926 .24 \\
\hline 2014 & 5.959 & 14.119 .655 .30 \\
\hline 2015 & 6.360 & 15.244 .467 .29 \\
\hline 2016 & 6.321 & 14.760 .444 .69 \\
\hline 2017 & 5.631 & 13.316 .472 .43 \\
\hline 2018 & 5.478 & 12.539 .492 .14 \\
\hline TOTALES & $\mathbf{3 5 . 5 4 8}$ & $\mathbf{8 2 . 8 9 9 . 4 5 8 , 0 9}$ \\
\hline
\end{tabular}

Fuente: Elaboración propia con datos facilitados por la Dirección General de Personas Mayores y Pensiones No Contributivas, de la Consejería de Igualdad, Políticas Sociales y Conciliación de la Junta de Andalucía.

La Tabla $n^{\circ} 4$ siguiente, que se ha confeccionada por orden del número de expedientes tramitados, nos pone de manifiesto situaciones parecidas a las comentadas en el caso de las Retrocesiones, siendo la más numerosa Sevilla y la más baja Jaén, de forma que las situaciones de irregularidad se presentan con más intensidad en Sevilla por razón de su mayor población, seguida por las provincias marítimas de Málaga, Cádiz y Almería, con la excepción de Huelva que ocupa el penúltimo lugar de la tabla, siendo las provincias de interior como Córdoba, Granada y Jaén, las que presentan un número menor de expedientes y por tanto, un menor volumen económico de prestaciones en reclamación. No es justificable lo que no tiene justificación, pero podemos encontrar alguna razón de peso para comprender la situación de las provincias marítimas, en el hecho de que han padecido con más fuerza el azote del paro y del desempleo de larga duración, agotándolo en la gran mayoría, pasando a situación de jubilación en condiciones muy precarias e inconsistentes de cotización, que determinaron en la mayoría de los casos, el pase a la percepción de prestaciones No Contributivas. 
$n^{\circ}$ 4.- Expedientes de reintegro por provincias 2013-2018

\begin{tabular}{cccccccc}
\hline PROVINCIA & $\mathbf{2 0 1 3}$ & $\mathbf{2 0 1 4}$ & $\mathbf{2 0 1 5}$ & $\mathbf{2 0 1 6}$ & $\mathbf{2 0 1 7}$ & $\mathbf{2 0 1 8}$ & TOTALES \\
\hline SEVILLA & 1467 & 1933 & 2162 & 1815 & 1291 & 1252 & 9.920 \\
\hline MÁLAGA & 1480 & 1270 & 1171 & 1167 & 1026 & 716 & 6.830 \\
\hline CÁDIZ & 597 & 785 & 897 & 919 & 723 & 868 & 4.789 \\
\hline ALMERIA & 633 & 630 & 580 & 670 & 653 & 650 & 3.816 \\
\hline GRANADA & 529 & 472 & 519 & 611 & 648 & 520 & 3.299 \\
\hline CÓRDOBA & 373 & 373 & 482 & 526 & 592 & 628 & 2.974 \\
\hline HUELVA & 321 & 306 & 266 & 316 & 384 & 451 & 2.044 \\
\hline JAÉN & 299 & 290 & 283 & 297 & 314 & 393 & 1.876 \\
\hline TOTALES & $\mathbf{5 . 6 9 9}$ & $\mathbf{6 . 0 5 9}$ & $\mathbf{6 . 3 6 0}$ & $\mathbf{6 . 3 2 1}$ & $\mathbf{5 . 6 3 1}$ & $\mathbf{5 . 4 7 8}$ & $\mathbf{3 5 . 5 4 8}$ \\
\hline
\end{tabular}

Fuente: Elaboración propia con datos facilitados por la Dirección General de Personas Mayores y Pensiones No Contributivas, de la Consejería de Igualdad, Políticas Sociales y Conciliación de la Junta de Andalucía.

\section{CONCLUSIONES}

\section{Dimensión económica.}

Es indudable la importancia económica que representa la recuperación o reintegro de prestaciones sociales indebidas para la estabilidad financiera del sistema, y es de tener muy en cuenta la agilidad o rapidez de los procedimientos, de cuya actividad depende el éxito de su resultado. Si los 35.548 expedientes instruidos en Andalucía entre los años objeto de estudio, como se recoge en la figura $\mathrm{n}^{\circ}$ 3 , se ha recuperado la nada despreciable suma de 83 millones de euros, semejante eficacia no sólo proporciona estabilidad económica y viabilidad financiera a este tipo de prestaciones, sino que aumenta el sentimiento de justicia y solidaridad entre la población, a la hora de percibir estas prestaciones no contributivas. Por tanto, la recuperación de estos recursos permite en principio disminuir el gasto público, así como estabilizar y darle continuidad al sistema y, por supuesto, es la mejor medida de lucha contra el fraude, de forma que la recuperación de estos recursos se produce de varias maneras:

- En los casos de modificación de cuantías de la pensión, a través de deducciones en devengos sucesivos de los pensionistas. 
- Por devolución de los propios perceptores, mediante ingreso en c/c de Recursos Diversos Territoriales de la TGSS.

- En el caso de fallecimiento del pensionista, por las entidades financieras a través de las que se percibieron.

- En otras prestaciones reconocidas en el Sistema de la Seguridad Social incompatibles en su cuantía con la prestación que se recibe.

\section{Efectos familiares}

Es importante destacar que una de las causas de extinción de la Prestación No Contributiva (PNC), que se produce con más frecuencia, es la de disponer de rentas o ingresos suficientes, ya sean personales o de la unidad económica de convivencia (UEC), y de ahí la importancia de informar las variaciones que pudieran concurrir con el beneficiario de una PNC. Es por ello que, a través de las distintas revisiones (anual, de oficio o a instancia de parte), se comprueba la permanencia o la variación de los requisitos exigidos para el derecho a las PNC, por lo que, de la revisión puede resultar la permanencia del derecho y de la cuantía percibida o, por el contrario, la modificación de la cuantía anteriormente reconocida, la extinción de la pensión, la suspensión del derecho o la suspensión del pago, y también puede derivarse un procedimiento para exigir el abono de atrasos o la obligación de reintegrar cantidades percibidas indebidamente. Estas revisiones se efectúan a partir de los datos obtenidos de los cruces de ficheros públicos, de la información recabada por los gestores de las pensiones, de la cedida por otras entidades gestoras y de los nuevos datos facilitados por los pensionistas, que al comienzo del nuevo año deben facilitar bajo declaración responsable.

Pero es que además, los beneficiarios de pensiones no contributivas están obligados a comunicar al organismo que gestiona su pensión, en el plazo de 30 días, todas aquellas variaciones que se produzcan en su unidad de convivencia, así como las que afecten al estado civil, residencia, recursos económicos propios y/o familiares y cuantos otros datos puedan tener incidencia en la conservación del derecho o en la cuantía de su pensión. El incumplimiento de esta obligación, voluntario o involuntario, provoca el reintegro de percepciones indebidas, lo que sin duda tiene evidente repercusión en la economía de la unidad familiar. 


\section{Utilidad de los controles}

Los controles en la percepción se consideran acertados, aunque se ha de reconocer también, la existencia de cierta dificultad de cobro en casos de insolvencia del perceptor que, en algunas ocasiones, ha sido falsa o aparente, siendo por ello obstáculo para que la TGSS no puede recuperar nada o casi nada. Ni tampoco en trámite de ejecución judicial. De todas formas, estas situaciones no son numerosas, y en una gran mayoría tienen su origen en errores y omisiones, intencionadas o no, aunque la picaresca no deja de actuar, como ocurre con las pensiones domiciliadas en cuenta bancaria en la que figura alguna persona autorizada por el/la titular. Hay que tener en consideración que hoy día, ha aumentado la conciencia social que rechaza la obtención y disfrute fraudulento de estas prestaciones, que son de eminente carácter social y destinadas a cubrir necesidades de pura subsistencia. Son por ello, prestaciones que se mueven entre la necesidad real y la tentación del fraude y, de entrada, son una llamada a todas aquellas personas que carecen de cotizaciones suficientes o que carecen totalmente de ellas, a veces porque no han hecho nada para solucionar su situación, y quieren subirse al carro de la "paga fácil" aunque sea pequeña. Pero no se puede generalizar, pues un número amplio de estos pensionistas han pasado toda su vida trabajando pero no han sido dados de alta por el tiempo realmente trabajado sino por otro inferior y,en bastantes casos, por ninguno. El resumen que se puede ofrecer es que han descendido bastante los expedientes de reintegro de prestaciones indebidas de PNC, en general, en las que se incluyen las de jubilación, invalidez y resto de ayudas sociales, tal y como se desprende de los datos contenidos en las Tablas 3 y 4 . Queda por recordar que la posibilidad de solicitar y obtener el fraccionamiento y aplazamiento en caso de reintegros de pensiones, se tramita ante la TGSS, que es la entidad gestora encargada de la Tesorería del Sistema, donde además, se sigue el procedimiento recaudatorio y, en el caso de ayudas sociales, las solicitudes de aplazamiento y fraccionamiento se presentan ante la Delegación de Igualdad, Políticas Sociales y Conciliación de la provincia de residencia del pensionista o, directamente, ante la Dirección General de Personas Mayores y Pensiones No contributivas de la Consejería de Igualdad y Políticas Sociales como órgano competente para resolverlas. 


\section{Propuestas y sugerencias}

Una de las propuestas que formulamos, es la de establecer cauces de información efectivos entre los Servicios Sociales Municipales y el Imserso, sobre todo, en ámbitos rurales y núcleos de población pequeños, cuya información sobre unidades de convivencia, residencia efectiva y empadronamiento, son una fuente de información de gran interés, para la revisión de estas prestaciones.

También sería muy interesante se creara dentro de la profesión de trabajo social una especialidad destinada a colaborar con los órganos de Inspección de Trabajo, con facultades de comprobación de situaciones irregulares y de extensión de informes para incoación posterior de actas de liquidación e infracción.

A título de mera sugerencia, sería conveniente que la Dirección General que esté encargada de las Pensiones No Contributivas, pudiera fiscalizar de oficio la situación económica, comprobar el estado civil así como la residencia del beneficiario de la PNC, en cualquier momento, mediante acceso a un punto de información restringido y reservado en exclusiva a estos órganos, que alcance a examinar no sólo datos fiscales de la AEAT, TGSS y SEPE, sino también de la Dirección General de Tráfico, Cuerpo Nacional de Policía -DNI, Catastro Inmobiliario Urbano y Rústico, Instituto Nacional de Estadística, Registro Civil y Otros, mediante la suscripción de convenios de colaboración entre el Ministerio del que dependa el órgano gestor de las prestaciones y los respectivos Ministerios de Hacienda, Economía, Trabajo, Interior, Igualdad, Justicia, etc., a fin de depurar la información contenida en los expedientes de concesión y poder contrastarla en todo momento, sin olvidar la colaboración que deben prestar obligatoriamente las entidades bancarias y de ahorro, en orden a la vigilancia y control del abono de dichas prestaciones, a menos de incurrir en responsabilidad civil subsidiaria en caso de fraude.

Ha sido publicada recientemente (abril 2019) una noticia sobre una sentencia del Tribunal Superior de Justicia de Navarra que condena a una mujer a 2 años de prisión y multa de 1.620 euros, por un delito de estafa, ya que estuvo 23 años cobrando la pensión de su madre fallecida en 1992, con un montante de 142.077.51 euros, que percibió a través de una cuenta en CaixaBank de la que era cotitular junto a la madre. La Audiencia Provincial de Navarra considera que ni Caja Navarra ni luego su sucesora CaixaBank realizaron controles de vigilancia de la titular del derecho a la percepción de la pensión, por lo que declara la responsabilidad civil subsidiaria de dicha enti- 
dad financiera. Situaciones como esta serán contadas, pero son demostrativas de falta de un mero o simple ejercicio de control, porque si la madre era pensionista desde 1979 y falleció en 1992, ¿qué edad tendría ahora?. Nada más que por mera curiosidad se hubiera detectado mucho antes la irregularidad. Ahora la entidad bancaria iniciará un proceso de regreso o repetición para intentar recuperar lo indebidamente cobrado por la condenada, ¿pero será solvente?

Las medidas que se proponen, aparte de facilitar un control rápido y exhaustivo de datos del perceptor, sobre residencia, ingresos, rendimientos económicos, inversiones, incrementos de patrimonio, signos externos de riqueza, etc. etc., tienen un indudable efecto disuasor sobre el peticionario que le impele a ser veraz y honesto en sus declaraciones y solicitudes, con lo que igualmente se gana en transparencia, eficiencia y equidad en el reparto de los recursos públicos, tal y como proclama el artículo 31.1 de nuestra Carta Magna.

\section{REFERENCIAS BIBLIOGRÁFICAS UTILIZADAS}

Almansa Pastor, J. M. : Derecho de la Seguridad Social, Tecnos. Madrid 1984.

Alonso Olea, M., y Tortuero Plaza, J.L.: Instituciones de Seguridad Social, Civitas, Madrid, $17^{\mathrm{a}}$ ed., 2000.

Boletín Oficial Del Estado núm. 68 de 20 de marzo de 2007, página 11872, que publica la Ley Orgánica 2/2007, de 19 de marzo, de reforma del Estatuto de Autonomía para Andalucía.

Boletín Oficial Del Estado núm. 236 de 01 octubre de 1980, que publica la Ley Orgánica 8/1980, de 22 de septiembre, de Financiación de las Comunidades Autónomas.

Cabanellas, G. : Diccionario Enciclopédico de Derecho Usual. Tomo VI. 27 ${ }^{\text {a }}$ Edición, libro de edición Argentina. Editorial Heliasta. 2001, págs. 385-386.

Constitución EsPaÑola. http://www.congreso.es. Consultado el 27 de febrero 2019.

Enciclopedia Jurídica Opus. Tomo VI. Ediciones Libra, C.A. Caracas - Venezuela. 2007, pag. 124.

Garcia Murcia, J.: La Seguridad Social en España y la idea de solidaridad. KRK Ediciones, Oviedo, 2017, pág. 11 
Guía Práctica de las Pensiones no Contributivas Para Profesionales DE LOS SERVicios SOCIALES. Junta de Andalucía. Consejería de Igualdad y Políticas Sociales. 2018.

Junta De Andalucía. Consejería de Igualdad, Políticas Sociales y Conciliación. https://www.juntadeandalucia.es/organismos/igualdadpoliticassocialesyconciliacion/areas/pensiones/pensiones-no-contributivas.html. Consultado el 20 de Mayo, 24 de Mayo y 4 de Julio de 2019.

Manual De Sentencias Pensiones No Contributivas Y PrestacioNES LISMI. Colección manuales y guías serie servicios sociales, $\mathrm{n}^{\circ}$ 33001. Ministerio del trabajo y asuntos sociales. Secretaria de estado de servicios sociales, familias y discapacidad. Imserso.

ORDEN DE 18.07.1997 para el desarrollo del RD 148/1996, de 5 de febrero, por el que se regula el procedimiento especial de reintegro de las Prestaciones de la Seguridad Social indebidamente percibidas (BOE núm. 180 de 29-07-1997).

Prestaciones Económicas. Informe Anual 2007. http://www.imserso.es/InterPresent2/groups/imserso/documents/binario/informeanual2007.pdf. Consultado el 19 de Mayo de 2019.

Prestaciones Indebidamente Percibidas De La Cotización Por La Gestión Recaudatoria De La Seguridad Social. https://www.iberley.es/temas/prestaciones-seguridad-social-indebidamente-percibidas-6511. Consultado el 13 de Abril de 2019.

REAL DeCRETo 148/1996, de 5 de febrero, que regula el procedimiento especial de reintegro de las prestaciones de la S.Social indebidamente percibidas.

Real Decreto Legislativo 8/2015, de 30 de octubre, por el que se aprueba el Texto Refundido de la Ley General de la Seguridad Social (BOE del 31 de octubre).

Real Decreto 357/1991, de 15 de marzo, por el que se desarrolla en materia de pensiones no contributivas la Ley 26/1990, de 20 de diciembre, por la que se establecen en la Seguridad Social prestaciones no contributivas (integrada en el Real Decreto Legislativo anterior) (BOE del 21 de marzo).

ReAL DeCRETO-Ley 28/2018, de 28 de diciembre, para la revalorización de las pensiones públicas y otras medidas urgentes en materia social, laboral y de empleo. 


\section{GLOSARIO DE FIGURAS}

\section{Págs}

Cuadro $\mathrm{N}^{\circ} 1$.- Cuantías por número de Convivientes.................529

Cuadro $\mathrm{N}^{\mathrm{o}} 2$.- Cuantías máximas............................................529

Cuadro $\mathrm{N}^{\circ}$ 3.- Importe máximo anual con más beneficiarios... 530

Tabla N ${ }^{\mathrm{o}}$ 1.- Retrocesiones (Fallecidos) 2013-2018....................538

Tabla N ${ }^{\circ}$ 2.- Expedientes de Retrocesión por Provincias............540

Tabla $\mathrm{N}^{\circ}$ 3.- Expedientes de Reintegro de Prestaciones

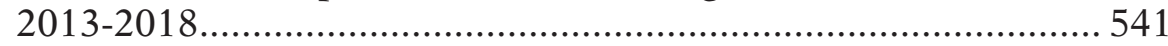

Tabla No 4.- Expedientes de Reintegro por Provincias.............. 542 